\title{
Inflation Co-Movement Dynamics: A Cross-Country Investigation Using a Continuous Wavelet Approach
}

\author{
Aviral Kumar Tiwari ${ }^{1}\left[\right.$, Emmanuel Joel Aikins Abakah ${ }^{2}$, Luis A. Gil-Alana ${ }^{3, *}{ }^{\mathbb{C}}$ and Moses Kenneth Abakah ${ }^{4}$ \\ 1 Rajagiri Business School, Rajagiri Valley Campus Rajagiri College of Social Sciences, Kochi 682039, India; \\ aviral.eco@gmail.com \\ 2 School of Economics, University of Cape Coast, Cape Coast CC-075-8216, Ghana; ejabakah@gmail.com \\ 3 Department of Econometrics and Quantitative Methods, School of Economics and Business Administration, \\ University of Navarra, 31009 Pamplona, Spain \\ 4 Economic and Risk Analysis Department, Central Securities Depository Ghana Limited, Accra 00233, Ghana; \\ mkabakah@gmail.com \\ * Correspondence: alana@unav.es
}

\section{check for} updates

Citation: Tiwari, Aviral Kumar, Emmanuel Joel Aikins Abakah, Luis A. Gil-Alana, and Moses Kenneth Abakah. 2021. Inflation

Co-Movement Dynamics: A Cross-Country Investigation Using a Continuous Wavelet Approach. Journal of Risk and Financial Management 14: 613. https:// doi.org/10.3390/jrfm14120613

Academic Editor: Thanasis Stengos

Received: 12 September 2021 Accepted: 30 November 2021 Published: 18 December 2021

Publisher's Note: MDPI stays neutra with regard to jurisdictional claims in published maps and institutional affiliations.

Copyright: (c) 2021 by the authors. Licensee MDPI, Basel, Switzerland. This article is an open access article distributed under the terms and conditions of the Creative Commons Attribution (CC BY) license (https:// creativecommons.org/licenses/by/ $4.0 /)$.

\begin{abstract}
The economic literature provides evidence that inflation rates can co-move across nations because of a host of reasons, ranging from low frequency changes in monetary policy to similar high frequency shocks. Hence, this paper investigates inflation rate co-movements between nine (9) African countries and their bilateral linkages with five (5) developed economies using continuous wavelets at different time scales or frequencies. Specifically, we examine the coherency and the phase relationship in time-frequency space in inflation rates of the selected countries. Several findings are documented. First, inflation rates co-movements in the nine African countries are time varying, multi-scale, and characterized by structural breaks. In addition, we find that inflation co-movements across countries in the Africa sub-region is weak at low frequencies. Furthermore, we find evidence of inflation co-movement between Africa and developed economies, suggesting that central banks and policy-makers in Africa need to monitor international price developments, and analyze their implications for their domestic economies. Second, we find that inflation rates in the selected African countries explain, on average, almost $80 \%$ of their own inflation variance over the whole sample period. Spillover analysis reveals that China and Canada account for a greater percentage of inflation variation in Africa.
\end{abstract}

Keywords: inflation rates; co-movement; wavelets; time frequency; Africa

\section{Introduction}

This paper examines how inflation rates in African countries are synchronized and linked to international inflation rates of some of the world largest economies: the US; Japan; the UK; China; and Canada. The literature on inflation co-movement fluctuation across countries has been growing from the perspective of academic researchers. For instance, Ciccarelli and Mojon (2010) have argued that a common factor could explain, on average, up to 70 percent of consumer price index (CPI) variation in countries. Similarly, Neely and Rapach (2008) posit that common and regional factors could explain 50 percent of the fluctuation in national inflation rates of countries. In a separate study, Monacelli and Sala (2009) found similar findings, and concluded that a common factor could account for about 15-30 percent of the variation in consumer prices.

The extant literature on co-movement of inflation across various countries has been attributed to a number of reasons, ranging from similar low-frequency changes in monetary policy to similar high-frequency shocks. The main reason that fuels inflation co-movement is that real economic activity is also correlated across countries. As a result, domestic inflation responds to correlated changes in the domestic demand, hence, co-movement in the business cycles could lead to commonality in inflation. Besides, adoption of similar monetary policies in the fixed exchange rate system may also push inflation rates across 
those countries that adopt similar monetary policy strategy. Consequently, a cross-section of studies asserts that in the absence of a fixed exchange rate system, the quest by central banks to stabilize rates could prompt central banks to reciprocate each other's policy shifts, hence, leading to inflation co-movement (Canzoneri and Gray 1985; Calvo and Reinhart 2002; Devereux and Engel 2007). In particular, Canzoneri and Gray (1985), in their paper Monetary Policy Games and the Consequence of Non-Cooperative Behavior, note that in an interdependent world, rational policymakers in one country may be expected to condition their actions on the policies pursued in other countries. Calvo and Reinhart (2002) analyzed the behavior of exchange rates, reserves, and interest rates to assess whether there is evidence that country practice is moving toward corner solutions, and found that many of the episodes that come under the heading of floating exchange rates look similar to many of the explicit less flexible exchange rate arrangements. Following (Neely and Rapach 2008; Henriksen et al. 2013), co-movement in inflation across countries could also be induced by similar monetary policy reaction functions across countries. On the international front, inflation commonality could also be induced by common macroeconomic shocks, such as shocks to oil prices and financial crises. It can be argued that central banks, in most cases, respond to shocks in a similar manner, which ends up fueling inflation co-movement (Henriksen et al. 2013). Also, macroeconomic shocks are often transferred from one country to another country's inflation rates as a result of international trading of assets and goods. In short, inflation rates co-move across countries due to different types of shocks from macroeconomics policies coupled with economic and political pressures, to which central banks often respond similarly.

Following the above considerations coupled with the fact that the African sub-region has become an investment destination in recent years for many international firms, it is essential that we establish whether inflation rates co-move across African countries and with the rest of the world for diversification purposes, hence, this study seeks to find out whether inflation rates in Africa co-move within a time-frequency framework. In other words, we show how co-movement in inflation in Africa occurs across frequencies, and further ascertain whether the co-movement in inflation across the selected countries is subject to frequency structural breaks over the sample period. To achieve the objective of the paper as addressed earlier on, the wavelet coherency approach was adopted to study the pair-wise co-variation in inflation rates for the selected countries at different frequencies, and further determine the essence of different frequencies in explaining inflation co-variation in the selected countries. The adopted approach, wavelet analysis, has been used in recent times to study relationships between several macroeconomic variables in the economic literature (e.g., Raihan et al. 2005; Crowley and Mayes 2009; Rua and Nunes 2009; Aguiar-Conraria and Soares 2011; Madaleno and Pinho 2012; Tiwari 2012, 2013; Dar et al. 2013; Tiwari et al. 2013a, 2013b, 2013c), for example, business cycles (Raihan et al. 2005), business cycle co-movement and synchronization in the Euro area (Crowley and Mayes 2009), co-movement in international stock markets (Rua and Nunes 2009), oil price changes and the macroeconomy (Aguiar-Conraria and Soares 2011; Tiwari 2013), price shock transmission in stock markets (Madaleno and Pinho 2012), interest rates and share prices (Tiwari 2012), producer price index and consumer price index (Tiwari 2013), and inflation synchronization among G7 economies (Tiwari et al. 2015).

Despite the enormous attention given to macroeconomic relationships in economics, the analyses of the co-movement of inflation rates across different frequencies in Africa is largely unexplored. To the best of our knowledge, this is the first study to examine inflation rate co-movement across countries in the African sub-region at different frequencies. The novelty of this paper rests on the application of wavelet analysis to provide a detailed analysis on inflation rate co-variation in Africa, and its linkages to developed countries at different frequencies. We thus contribute significantly to the existing literature that measures national inflation rate synchronization at different frequencies using the wavelet coherency approach. The analysis will help us ascertain the extent of inflation co-movement at different stages, and whether co-movement is concentrated at the very 
quickly fluctuating, quickly fluctuating, or the slowly fluctuating components of inflation. We calculate the wavelet coherency for all studied pairs of countries to determine the variation in inflation rates across different frequencies for the period under study.

The theoretical underpinnings in the co-movement of inflation show that inflation rates tend to co-move together across countries. However, there is no consensus as to how inflation co-moves across countries. The prior literature on inflation co-movement is very limited because the majority of these studies use different models to evaluate the co-movement of inflation rates. For instance, Kose et al. $(2003,2008)$ used the dynamic latent factor to study international co-movements in real macroeconomies, whereas Wang and Wen (2007) tested whether co-movement in inflation rates is higher than other variables using the calibrated New Keynesian two-country models. Again, using factor models, Mumtaz et al. (2011) decomposed sectorial national inflation rates into world and national components. Monacelli and Sala (2009), however, illustrated that international spillovers of inflation are weak and, therefore, cannot be considered as attributes of inflation comovement. Besides, in direct terms, trade channel inflation co-movement can increase and decrease import prices, and, thus, serves an indirect pro-competitive effect, which reduces the pricing power of domestic firms (Bernanke 2007). Domestic inflation is greater in countries that have a greater dependency on central banks, mainly due to common inflation factors (Neely and Rapach 2008). For instance, in Neely and Rapach's (2008) study, they indicated that world and regional factors are the main factors that explain inflation variability across 64 countries. Again, taking a cue from Beck et al.'s (2009) study, "Euroarea effects" accounts for variation in the prices of regional economies. However, Eickmeier and Moll (2009) follow a different approach by estimating factor-augmented Phillips curves for 24 OECD economies. Several common factors drive co-movements in inflation. This study examines that a common component to changes in unit labor and business cycle correlations are the significant determinant of inflation. A prior study suggested that, on average, close to $70 \%$ of the variation in a country's inflation can be explained by a common factor (Ciccarelli and Mojon 2010). Overall, the empirical evidence using different methodologies provides mixed evidence on inflation co-movement in different countries.

The remaining part of the paper is organized as follows: Section 2 documents the methodology and data description, whereas Sections 3 and 4 discuss the empirical results and concluding remarks, respectively.

\section{Data Source and Empirical Methodology}

\subsection{Data Source}

For the purposes of this study, monthly consumer price indexes (CPI) of nine selected African countries, South Africa, Egypt, Nigeria, Kenya, Tunisia, Ghana, Botswana, Mauritius, and Namibia; as well as from five developed economies, the USA, the UK, Japan, Canada and China, were obtained from DataStream for the period of January 2000 to June 2018, and considered for the construction of the inflation variable. The CPI was used to construct the inflation rate of these economies. We chose the nine African countries because they represent a group from all regions on the continent with active financial markets and institutions.

\subsection{Empirical Methodology}

We analyzed inflation rate co-movement across the selected countries due to its implications in both monetary and fiscal policies in the selected countries. However, what is more important is that the variation in inflation rates across countries occurs at different frequencies, caused by several factors, such as: short-term, medium-term or long-term shocks and fundamentals, such as monetary policy transmission lag; and the operation purchasing power parity rule, which could fuel inflation rate co-variation. Gabor (1946) documented several limitations of conventional approaches such as the windowed Fourier decomposition analysis often used in time series analysis to extract different frequencies, since the time frequency localization of the Fourier approach is imperiled. In 
view of the limitation of the conventional approaches, for this study, we adopted a wavelet transform, which putrefies time series into narrow and wide functions during periods of high frequency and low frequency, respectively (Daubechies 1992). Consequently, the putrefaction results in a trade-off for the time scale resolution, permitting good localization in both time as well as frequency.

\subsubsection{The Continuous Wavelet Methodology}

The wavelet transform approach decomposes signals into dilated and translated functions referred to as mother wavelets $\mathrm{u}(\mathrm{t})$. The mother wavelet is expressed as a function of two constructs where one focuses on time position (s), with the other parameter focusing on the scale of the wavelets. Hence, a time series $x(t)$ that has been subjected to the wavelet transform decomposition with reference to the selected mother wavelet is presented in Equation (1):

$$
W_{x}(a, \tau)=\frac{1}{\sqrt{a}} \int_{-\infty}^{+\infty} x(t) \varphi^{*}\left(\frac{t-\tau}{a}\right) d t=\int_{-\infty}^{+\infty} x(t) \varphi_{a, \tau}^{*}(t) d t
$$

Here, $W x(a, \tau)$ denotes the influence of the scales, whereas * denotes the influence of the complex conjugate form leading to a two-dimensional surface denoted as $\Re\left(W_{x}(a, \tau)\right)$.

The wavelet approach adopted for this paper rests on several considerations. Nevertheless, Mallat (1998) posits that the best methodology to consider in examining quantitative information about phase connections that exist between two time series is continuous and complex wavelets. In the literature, the two most referenced continuous wavelets are the "Mexican hat" and the "Morlet wavelet". High frequency resolution is associated with the Morlet wavelet, since its scales and frequencies are highly localized. However, in the case of the Mexican hat, frequency localization is poor, but it has good time localization.

In this paper, the Morlet wavelet is adopted for the purposes of the study:

$$
\varphi(t)=\pi^{-1 / 4} \exp \left(-i 2 \pi f_{0} t\right) \exp \left(-t / 2^{2}\right)
$$

Under the Morlet wavelet, the nexus amid the wavelet scale and the frequency is outlined below $\frac{1}{f}=\frac{4 \pi a}{\omega_{0}+\sqrt{2+\omega_{0}^{2}}}$ with $\omega_{0}$ about $2 \pi$.

For the Morlet wavelet, the studied signal is separated into phase and amplitude, since it can be factored into an imaginary and a real part. We write a complex wavelet coefficient $W_{x}(a, \tau)$, with reference to its phase $\phi_{\mathrm{x}}(a, \tau)$ and modulus $\left|W_{x}(a, \tau)\right|$.

We discretized Equation (1) for time series $\left\{x_{n}: \mathrm{n}=1 \ldots \mathrm{N}\right\}$ for practical purposes, as shown below:

$$
W_{x}^{n}(a, t)=\frac{\delta t}{\sqrt{a}} \sum_{n=0}^{N-1} x_{n} \cdot \varphi^{*}\left((m-n) \frac{\delta t}{a}\right), m=1,2, \ldots, N-1
$$

From Equation (2), $\delta t$ denotes the uniform step size. Following Torrence and Compo (1998), we explored the expediency presented discrete Fourier transform by discretizing the wavelet transform, as presented below:

$$
W_{x}^{n}(a, t)=\frac{\delta t}{\sqrt{a}} \sum_{n=0}^{N-1} \hat{x}_{n} \cdot \varphi^{*}\left(a \omega_{m}\right) e^{i \omega k n \delta t}, m=0,1,2, \ldots, N-1
$$

A set of scales necessary for use in the wavelet transform was obtained using the formula below:

$$
a_{j}=a_{0} 2^{j \delta t}, \quad j=0,1, \ldots, J
$$

where $J=\delta j^{-1} \log _{2}\left(N \delta t / a_{0}\right)$. $a_{0}$ denotes the least resolvable scales which is chosen to ensure that the corresponding Fourier period is about $2 \delta t$. 


\subsubsection{Wavelet Power Spectrum, Wavelet Coherency, and Phase Difference}

With spectral approaches, we compute the localized wavelet power spectrum as:

$$
S_{x}(f, \tau)=\|W(f, \tau)\|^{2}
$$

We employ the wavelet cross spectrum and the wavelet coherence to compute the relation amid the two time series that are non-stationary.

The wavelet cross-spectrum employed in this study is given by:

$$
W_{x, y}(f, \tau)=W_{x}(f, \tau) W_{y}^{*}(f, \tau)
$$

On the other hand, we denote the wavelet coherency as:

$$
R_{x, y}(f, \tau)=\frac{\left\|\left\langle W_{x, y}(f, \tau)\right\rangle\right\|}{\left\|\left\langle W_{x, x}(f, \tau)\right\rangle\right\|^{1 / 2}\left\|\left\langle W_{y, y}(f, \tau)\right\rangle\right\|^{1 / 2}}
$$

where \langle\rangle represents a smoothing operator in both scale and time. Based on this definition, $R_{x, y}(f, \tau)$ is restricted by $0 \leq R_{x, y}(f, \tau) \leq 1$. Following, Liu (1994) we see that the benefits of wavelet coherency rest on its difference in time and, therefore, its capacity to identify a transitory relationship amid the two time series. We compute the phase difference $\phi_{x, y}(f, \tau)$ as shown below:

$$
\phi_{x, y}(f, \tau)=\tan ^{-1} \frac{\Im\left(\left\langle W_{x, y}(f, \tau)\right\rangle\right)}{\Re\left(\left\langle W_{x, y}(f, \tau)\right\rangle\right)}
$$

From the phase difference, we obtain the linkages existing in the two series both in phase and out of phase. We then use Monte Carlo approaches to test whether the wavelet patterns displayed by the wavelet approach are statistically significant.

\subsubsection{Spillover analysis}

To estimate the forecast error variance decomposition, we rely on the Diebold and Yilmaz spillover index, which relies on a vector autoregressive (VAR) model. To overcome the sensitivity relating to the ordering of the endogenous variables, instead of using the Cholesky decomposition, we employ an ordering-invariant generalized variance decomposition. We compute the Diebold and Yilmaz (2012) spillover index as follows, where we denote $\boldsymbol{X}_{t}$ as a $14 \times 1$ vector of series representing CPI inflation rates for the selected 14 countries. We compute a VAR $(p)$ model that denotes the changing aspects existing in this association as follows:

$$
\mathbf{X}_{t}=\sum_{i=1}^{p} \boldsymbol{\Theta} \mathbf{X}_{t-i}+\varepsilon_{t}, \varepsilon_{t} \sim \mathbf{N}(\mathbf{0}, \Sigma)
$$

where $\varepsilon_{t}$ is the error vector, and $\Sigma$ is the associated $14 \times 14$ variance-covariance matrix. For this $\operatorname{VAR}(p)$ model, the moving average (MA) demonstration is $\mathbf{X}_{t}=\sum_{i=0}^{\infty} \mathbf{A}_{i} \varepsilon_{t-i}$ where $\mathbf{A}_{i}$ is recursively estimated as:

$$
\mathrm{A}_{i}=\Theta_{1} \mathrm{~A}_{i-1}+\Theta_{i-2}+\ldots+\Theta_{p} \mathrm{~A}_{i-p}
$$

The H-step-ahead generalized forecast error variance decomposition is computed using the formula below:

$$
\theta_{i j}(\boldsymbol{H})=\frac{\sigma_{i i}^{-1} \sum_{h=0}^{H-1}\left(\boldsymbol{s}_{i}^{\prime} \boldsymbol{A}_{h} \sum s_{j}\right)^{2}}{\sum_{h=0}^{H-1}\left(\boldsymbol{s}_{i}^{\prime} \boldsymbol{A}_{h} \sum A_{h}^{\prime} s_{i}\right)}
$$


where $\sigma_{i i}$ is the I element on the principal diagonal of $\boldsymbol{\Sigma}$. As each row of $\theta_{i j}(\boldsymbol{H})$ does not generally sum to 1 , it is important to normalize as:

$$
\widetilde{\theta}_{i j}(\boldsymbol{H})=\frac{\theta_{i j}(\boldsymbol{H})}{\sum_{j=1}^{\boldsymbol{N}} \theta_{i j}(\boldsymbol{H})} \text { so that } \sum_{j=1}^{N} \widetilde{\theta}_{i j}(\boldsymbol{H})=1 \text { and } \sum_{i, j=1}^{N} \widetilde{\theta}_{i j}(\boldsymbol{H})=N
$$

Diebold and Yilmaz (2012) endorse calculating the total spillover as follows:

$$
S(H)=\frac{\sum_{\substack{j=1 \\ i \neq j}}^{N} \widetilde{\theta}_{i j}(\boldsymbol{H})}{N} \cdot 100
$$

For the purpose of this study, we focus on the directional flow of inflation rate spillover received by each country (I) from all other members of countries in our sample. We compute this as follows:

$$
S_{i, o}(H)=\frac{\sum_{\substack{j \neq 1 \\ i \neq j}}^{N} \widetilde{\theta}_{i j}(\boldsymbol{H})}{\sum_{j=1}^{N} \widetilde{\theta}_{i j}(\boldsymbol{H})} \cdot 100
$$

\section{Data Analysis and Empirical Findings}

For the purposes of testing inflation rate co-movement in the African sub-region and the rest of the world, monthly inflation rates of nine selected African countries and five advanced economies were examined over the period of January 2000 to June 2018. Table 1 summarizes the descriptive statistics of the inflation rate series. We find that the sample mean is positive for each series, and for countries in Africa, the highest mean was recorded by Nigeria (0.9981), with the UK (0.1762) recording the highest mean for the developed economies. For the skewness, we find that, with the exception of Tunisia, all other African countries employed in the study recorded positive skewness. However, for the advanced economies, the results show negative skewness for the UK, the USA, China, and Canada, with Japan recording a positive skewness of 2.1615. The distributional properties of the inflation rate series document extreme observations. The highest kurtosis in the sample was recorded by Japan (18.8088), with the lowest recorded by Tunisia (3.0989). The kurtosis of all series exceeds the threshold of 3 , which implies that all the series have flatter tails as expected from a normally distributed variable. The JB test of normality rejects the normality assumption for all countries except Tunisia and Canada.

Inflation rate series for all countries are plotted in Figure 1, with a simple correlation between the series also presented in Table 2. It is evident from Figure 1 that all the series are not stationary, and have a trend in their movement. The plots document increasing and decreasing trends for all the inflation rate series under study. For the simple correlation between the series presented in Table 2, for the developed economies, with the exception of the UK and China which depict a negative relationship, all the remaining countries recorded a positive correlation. For the nine selected African economies, we see that the inflation rates series of Tunisia is negatively correlated with all countries, with the exception of Egypt where the link between Tunisia and Egypt was seen to be positive. For the simple correlation between African countries and developed economies, we find mixed results for the linkages between inflation rates in Africa and in advanced economies.

To commence analysis on the co-movement of inflation between African countries and their bilateral linkages with selected developed economies, we began by plotting the wavelet power spectrum of inflation rates in the countries under study, with results presented in Figures 2 and 3. ${ }^{1}$ Figure 2 presents findings for the selected African countries, whereas Figure 3 shows a wavelet power spectrum of inflation rates ${ }^{2}$ for the developed economies. 
Table 1. Summary statistics of CPI-based inflation for the selected nine African and five developed economies.

\begin{tabular}{|c|c|c|c|c|c|c|c|c|c|c|c|c|c|c|}
\hline & Botswana & Egypt & Ghana & Kenya & Mauritius & Namibia & Nigeria & $\begin{array}{l}\text { South } \\
\text { Arica }\end{array}$ & Tunisia & Canada & China & Japan & UK & USA \\
\hline Mean & 0.5719 & 0.7908 & 1.2855 & 0.6598 & 0.4050 & 0.5199 & 0.9981 & 0.4763 & 0.3293 & 0.1624 & 0.0108 & 0.0061 & 0.1762 & 0.1788 \\
\hline Median & 0.4022 & 0.5813 & 1.1510 & 0.5604 & 0.3300 & 0.4169 & 0.8044 & 0.4073 & 0.3398 & 0.1808 & - & - & 0.2345 & 0.1867 \\
\hline Maximum & 3.2053 & 4.8519 & 10.8711 & 5.1881 & 3.0337 & 3.2263 & 7.3906 & 1.8779 & 1.1403 & 1.1542 & 2.0608 & 1.7418 & 0.9996 & 1.3768 \\
\hline Minimum & -0.6650 & -1.5903 & -2.5743 & -2.4209 & -2.4623 & -1.3739 & -3.3632 & -0.8264 & -0.5914 & -1.0372 & -2.5743 & -0.6122 & -0.8839 & -1.7705 \\
\hline Std. Dev. & 0.5279 & 0.9495 & 1.5438 & 1.0033 & 0.6884 & 0.5579 & 1.4091 & 0.4490 & 0.3191 & 0.3735 & 0.6030 & 0.2230 & 0.3490 & 0.3011 \\
\hline Skewness & 1.4802 & 1.0154 & 1.5385 & 0.7136 & 0.5604 & 1.1847 & 0.6407 & 0.5495 & -0.0146 & -0.1629 & -0.3104 & 2.1615 & -0.7784 & -1.2863 \\
\hline Kurtosis & 6.6503 & 5.1324 & 10.4073 & 5.9709 & 6.5047 & 6.6079 & 6.7021 & 3.4375 & 3.0989 & 3.3158 & 4.7271 & 18.8088 & 3.8397 & 12.0504 \\
\hline Jarque-Bera & 202.4852 & 79.4900 & 589.7443 & 99.5739 & 124.1102 & 170.7852 & 140.6847 & 12.8266 & 0.0974 & 1.8872 & 30.8744 & 2462.2160 & 28.6823 & 811.5060 \\
\hline Observations & 220 & 220 & 220 & 220 & 220 & 220 & 220 & 220 & 220 & 220 & 220 & 220 & 220 & 220 \\
\hline
\end{tabular}

Table 2. Correlation of CPI-based inflation.

\begin{tabular}{|c|c|c|c|c|c|c|c|c|c|c|c|c|c|c|}
\hline & Botswana & Egypt & Ghana & Kenya & Mauritius & Namibia & Nigeria & $\begin{array}{l}\text { South- } \\
\text { Africa }\end{array}$ & Tunisia & Canada & China & Japan & UK & USA \\
\hline Botswana & 1 & & & & & & & & & & & & & \\
\hline Egypt & -0.0205 & 1 & & & & & & & & & & & & \\
\hline Ghana & 0.1712 & -0.1206 & 1 & & & & & & & & & & & \\
\hline Kenya & 0.1718 & 0.0731 & 0.1714 & 1 & & & & & & & & & & \\
\hline Mauritius & 0.1444 & 0.0329 & 0.0073 & 0.0516 & 1 & & & & & & & & & \\
\hline Namibia & 0.2531 & 0.1428 & 0.1964 & 0.0679 & 0.2310 & 1 & & & & & & & & \\
\hline Nigeria & 0.1505 & -0.0328 & 0.0413 & 0.0215 & 0.0275 & 0.0439 & 1 & & & & & & & \\
\hline South-Africa & 0.2384 & 0.2005 & 0.0847 & 0.0592 & 0.1963 & 0.4464 & 0.1140 & 1 & & & & & & \\
\hline Tunisia & -0.0276 & 0.0949 & -0.1848 & -0.0777 & -0.0923 & 0.0004 & -0.0530 & -0.2407 & 1 & & & & & \\
\hline Canada & 0.3073 & -0.0165 & 0.1142 & 0.0511 & -0.0690 & 0.0219 & 0.0699 & 0.3306 & -0.1081 & 1 & & & & \\
\hline China & -0.0116 & 0.0199 & 0.0240 & 0.0696 & 0.0328 & -0.0618 & -0.0040 & -0.0185 & 0.0408 & 0.0976 & 1 & & & \\
\hline Japan & -0.0024 & 0.0726 & -0.0766 & 0.0649 & 0.0139 & -0.0790 & -0.0876 & 0.0376 & 0.1155 & 0.1281 & 0.0270 & 1 & & \\
\hline UK & 0.2657 & 0.0298 & -0.0270 & 0.2127 & -0.0088 & 0.2100 & 0.0327 & 0.1500 & 0.2469 & 0.2599 & -0.0083 & 0.0184 & 1 & \\
\hline USA & 0.2630 & 0.0929 & -0.0097 & -0.0065 & 0.0948 & 0.1321 & -0.0046 & 0.2858 & -0.0353 & 0.5829 & 0.1143 & 0.2694 & 0.2075 & 1 \\
\hline
\end{tabular}


In the wavelet power spectrum of inflation presented in Figure 2 for the selected African countries, we find that Nigeria, Egypt, Kenya, Tunisia, Botswana, Mauritius, and Namibia have common features of higher time scales between 4-9 year time scales, with Ghana recording the highest time scales of 8-12 years. For the advanced economies, the wavelet power spectrum of inflation presented in Figure 3 reveals lower time scales between 2-4 years for the US, the UK, Japan, China, and Canada. However, it is noteworthy to surmise that because we take the absolute value of the imaginary part which fuels loss of information, the wavelet power spectrum is not a robust and sophisticated method to investigate inflation co-movement. Due to the limitation in the wavelet power spectrum (WPS, hereafter) tool, one is not certain that inflation will co-move or synchronize even if the two countries share a similar power region. To overcome the limitation of the wavelet power spectrum tool, we employed wavelet coherency using a Morlet wavelet to estimate local synchronization of inflation at different frequencies.

Results from the wavelet coherency using a Morlet wavelet plotted by contour plots with the output depicting three dimensions of frequency, time, and the wavelet coherency are presented in Figure 4 to examine the synchronization of inflation between the nine African countries. From the output of the exercise, the wavelet coherency is represented by the red-blue scale color spectrum, where an increasing value of wavelet coherency matches up with a deepening red color. Using wavelet decomposition, the vertical and horizontal axes represent time and frequency (denoted by time scales) of the time series. We then analyze the time and frequency varying inflation rate co-movement between each pair of the nine selected African countries by visually assessing the graphs. From the results, we find that the wavelet coherency is statistically significant at $5 \%$ for the isolated regions. In addition, we also find the prevalence of the edge effects for some regions. Following Torrence and Compo (1998), ${ }^{3}$ regions affected by edge effects are referred to as the "cone influence" (COI). It is important to note that the region beneath the cone lacks accuracy of spectral information, and as a result, should be cautiously interpreted. We thus test the significance of the results statistically by estimating wavelet coherency using the Monte Carlo method. The Monte Carlo method employed involves constructing a large ensemble of surrogate data set pairs with the same AR1 coefficients as the input data set. The wavelet coherency for each pair is then estimated, with statistical significance estimated for each scale by employing only values in the COI. The plots of wavelet coherency are shown in Figure 4 for inflation co-movement between the selected African countries, whereas Figure $5^{4}$ documents inflation rate co-movement between the nine selected African countries and the developed economies. It must be noted that strong inflation rate co-movement at high (low) frequencies is the dark red area at the top (bottom), whereas a dark red area at the right-hand (left-hand) side signifies strong co-movement at the end (start) of the sample period. We use a frequency scale which is interpreted in terms of time to distinguish inflation rate co-movements between different time scales (frequencies).
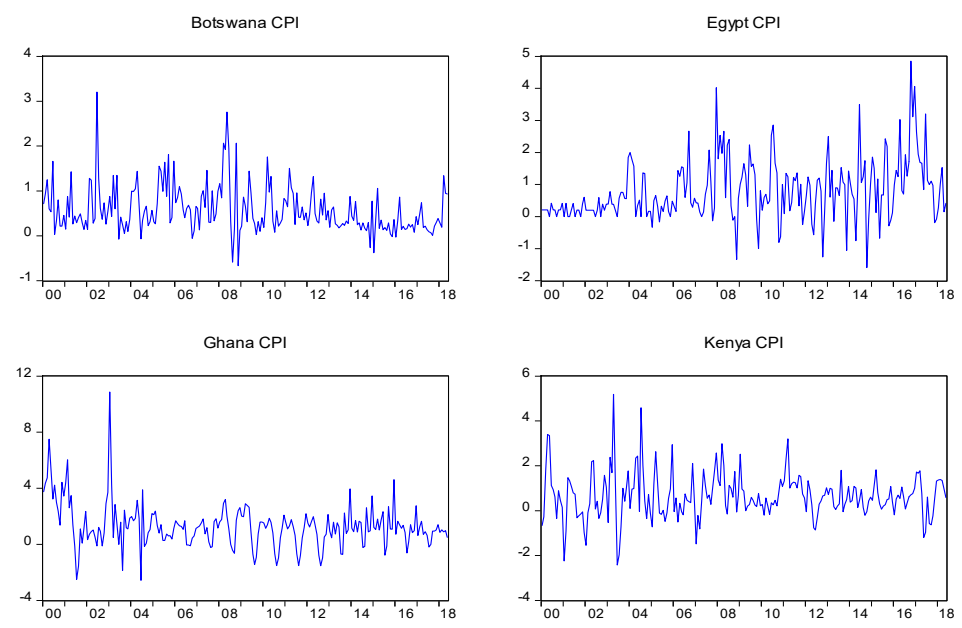

Figure 1. Cont. 

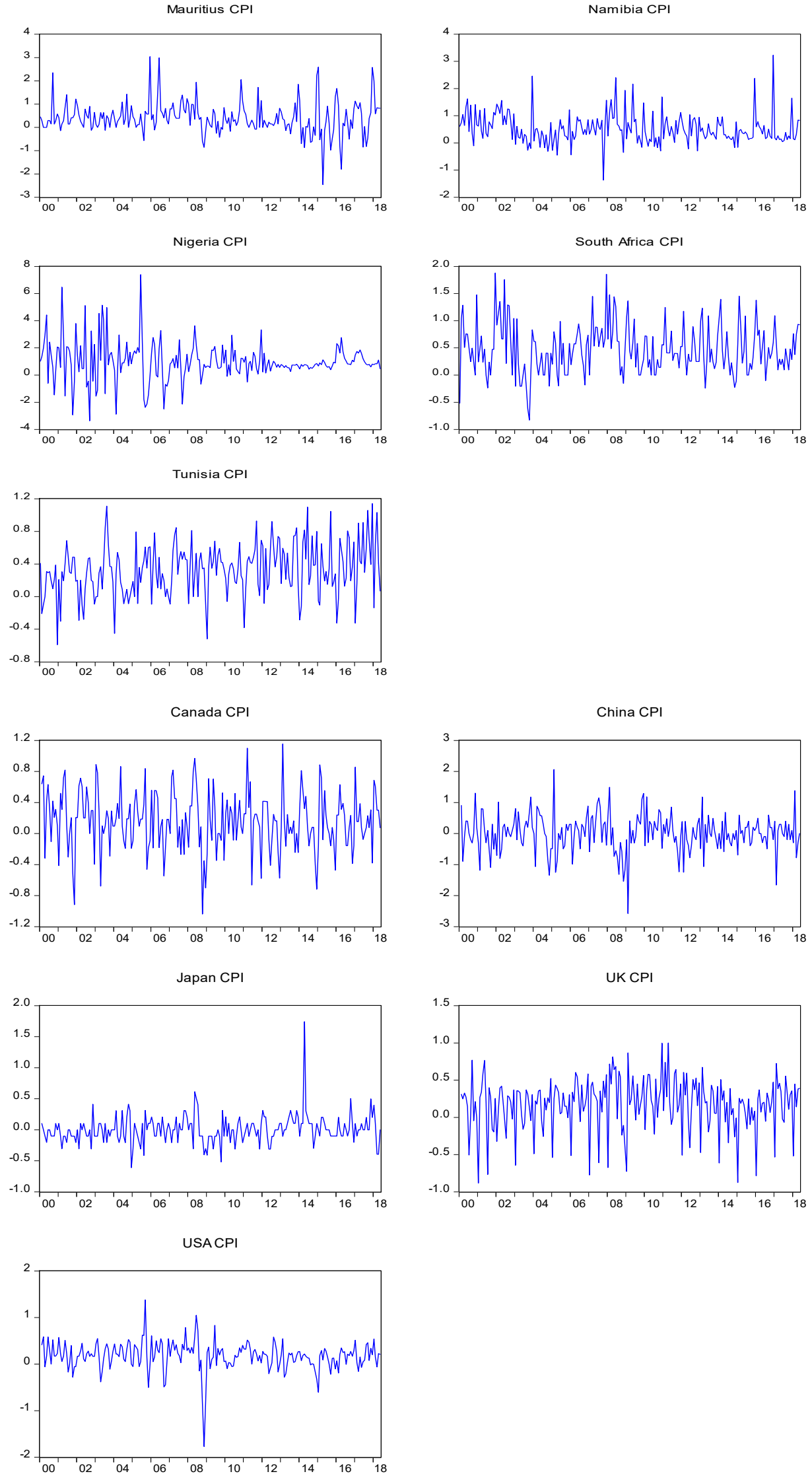

Figure 1. Plot of CPI-based inflation for the selected nine African and five developed economies. 


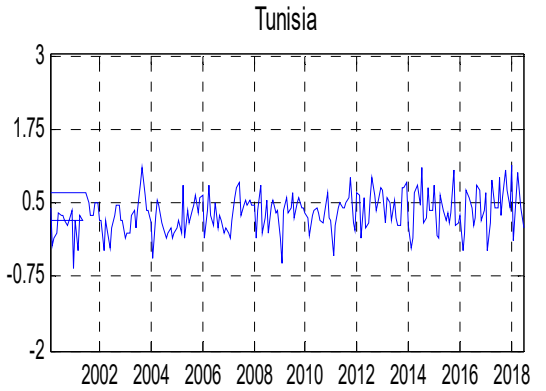

Botswana

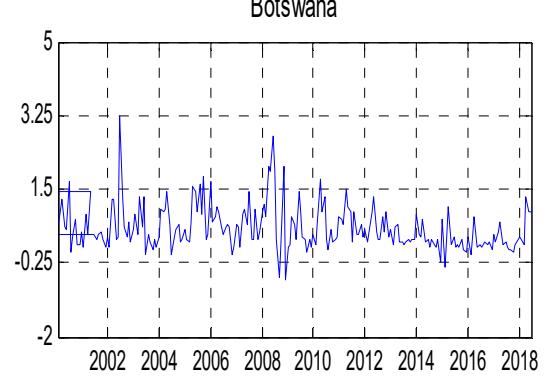

Mauritius
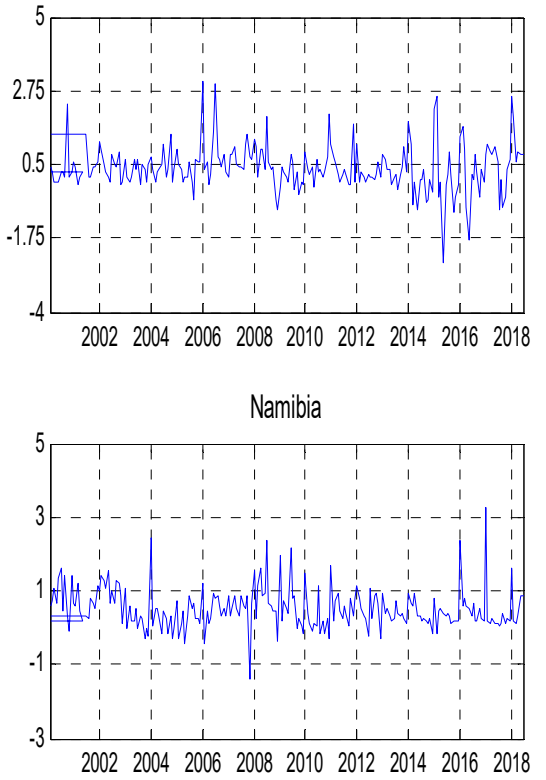

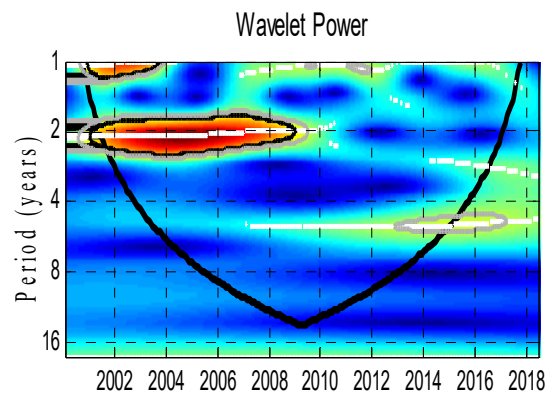

Wavelet Power

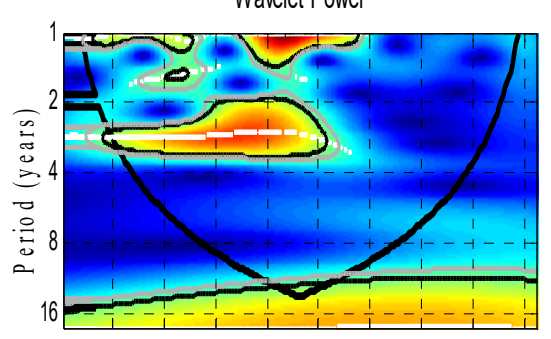

200220042006200820102012201420162018
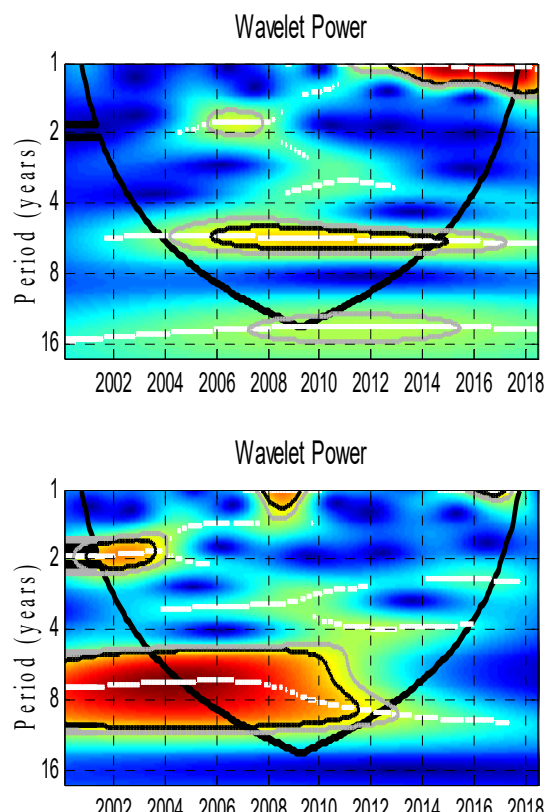

200220042006200820102012201420162018

Figure 2. Cont. 

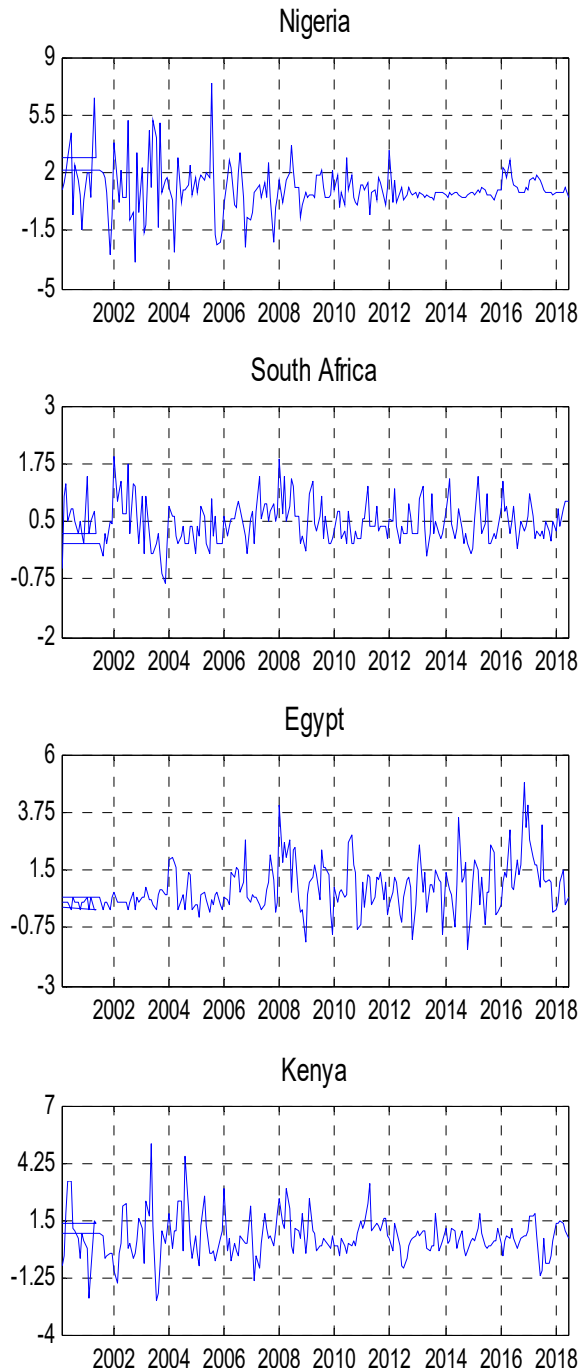

Ghana

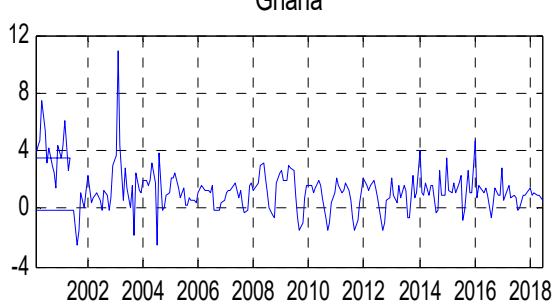

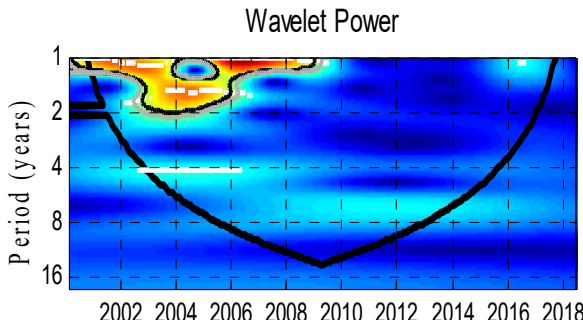

Wavelet Power

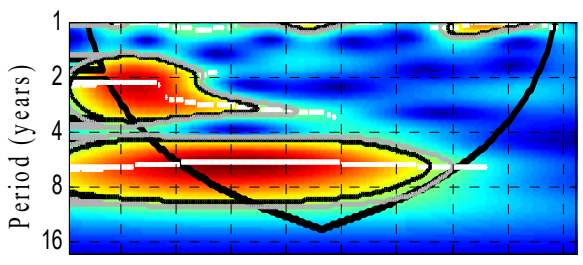

200220042006200820102012201420162018

Wavelet Power

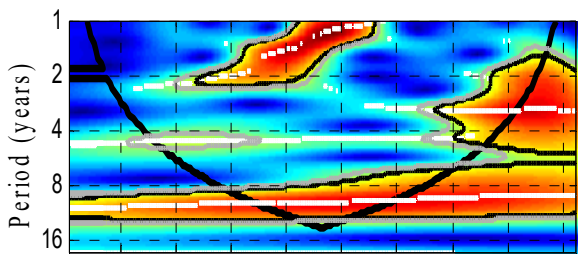

200220042006200820102012201420162018

Wavelet Power

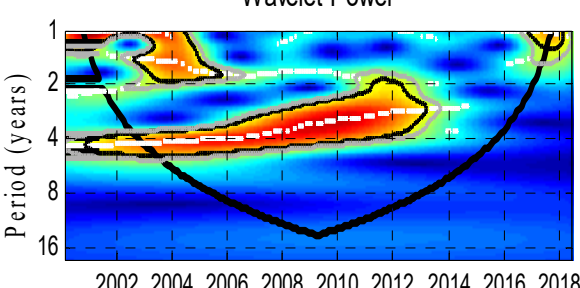

Wavelet Power

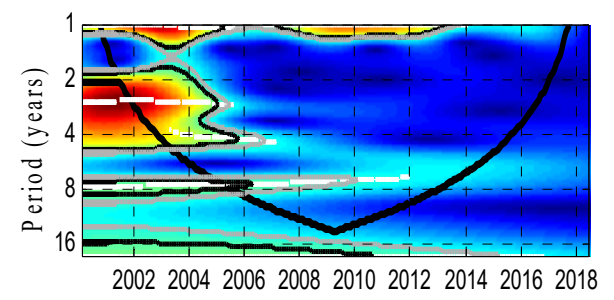

Figure 2. Wavelet power spectrum of inflation rates in selected nine African countries. 
USA

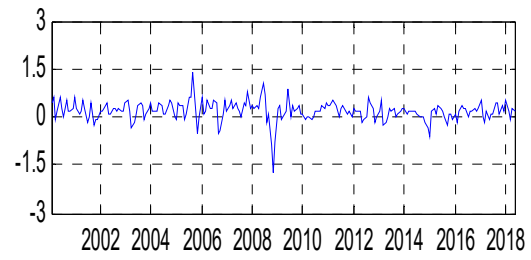

Japan

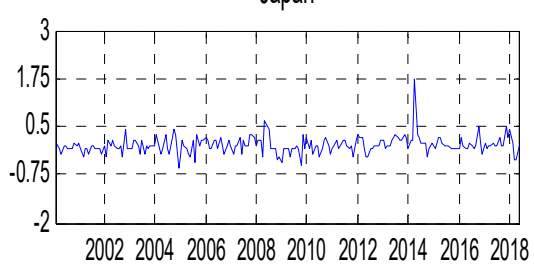

UK

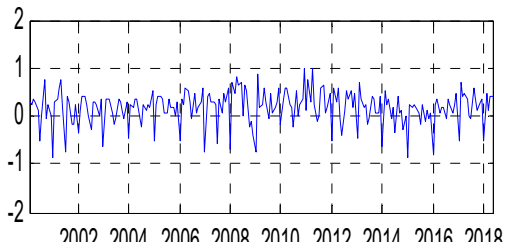

200220042006200820102012201420162018

China

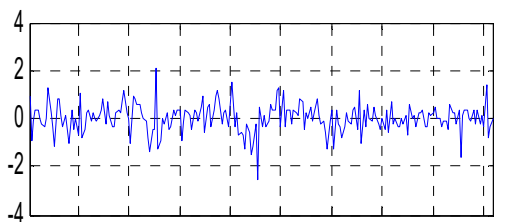

200220042006200820102012201420162018

Canada

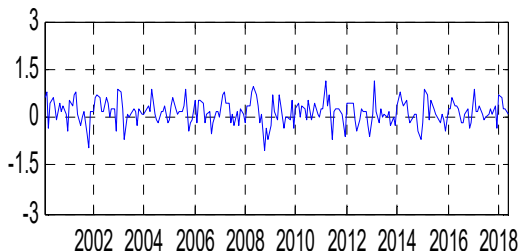

Wavelet Power

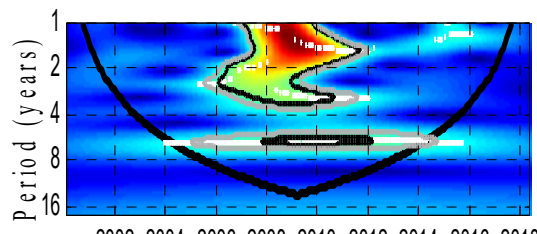

200220042006200820102012201420162018 Wavelet Power

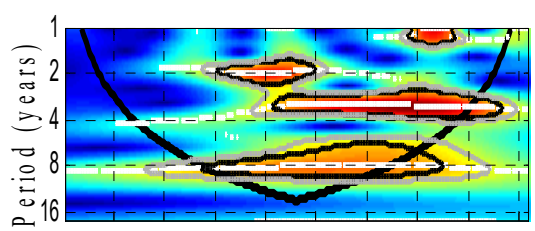

200220042006200820102012201420162018 Wavelet Power

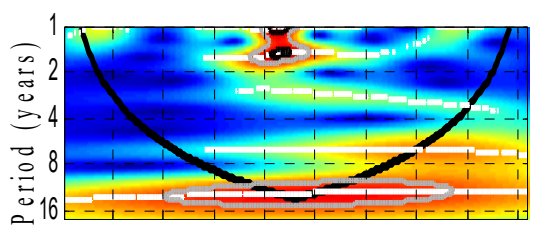
200220042006200820102012201420162018 Wavelet Power

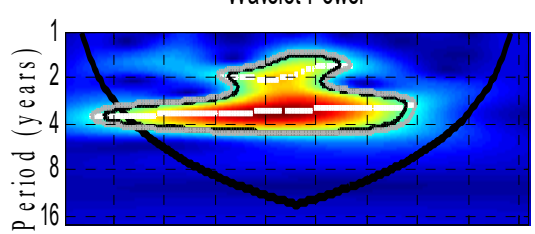

200220042006200820102012201420162018 Wavelet Power

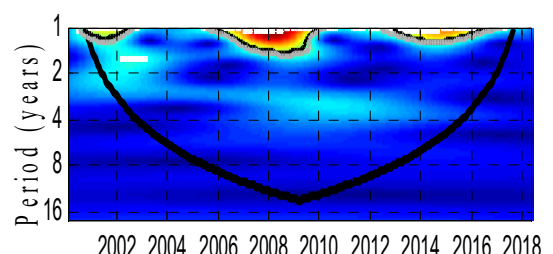

Figure 3. Wavelet power spectrum of inflation rates in selected five advanced countries. 
2.(a)WTC: Nigeria-South Africa
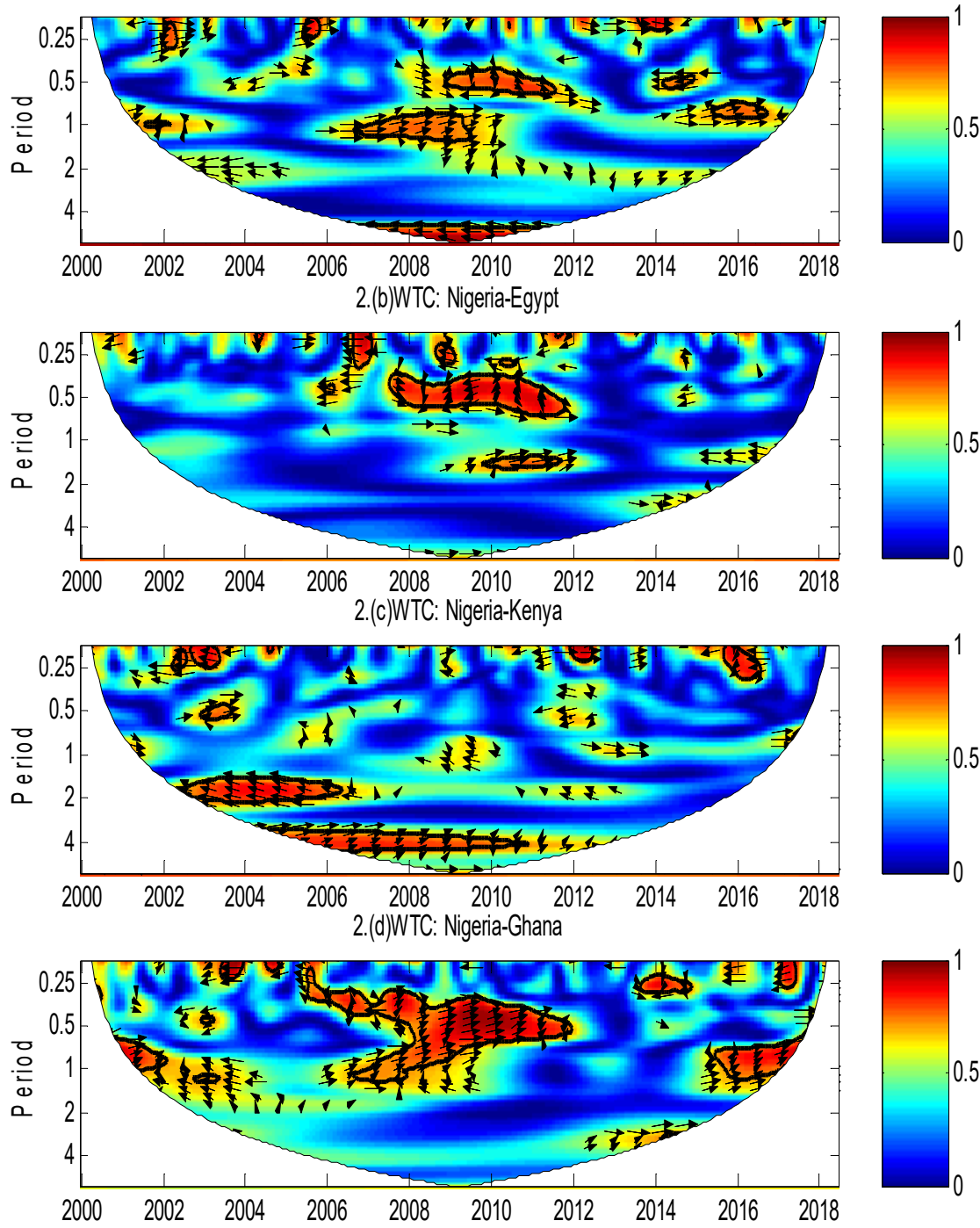

Figure 4. Cont. 

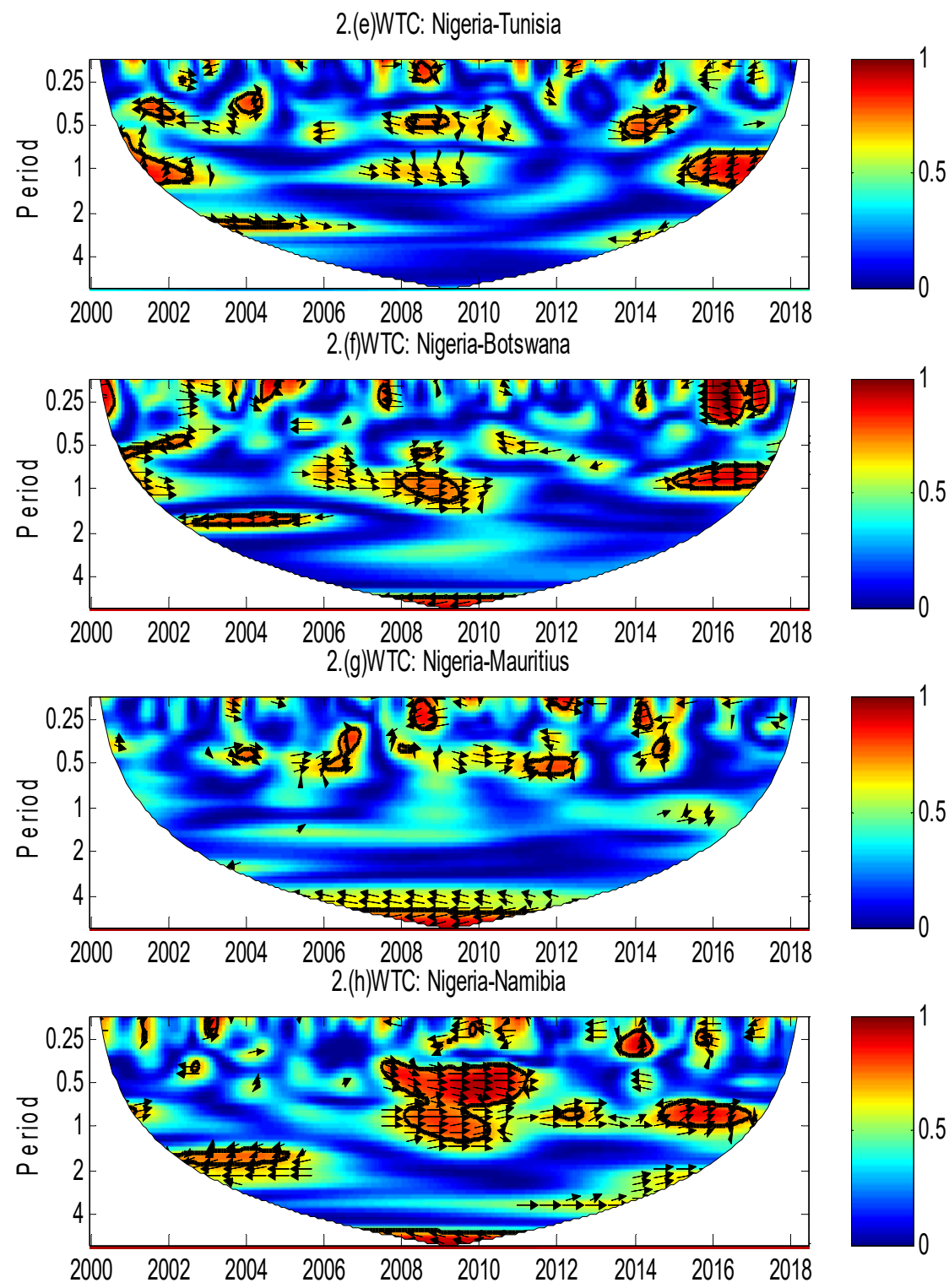

Figure 4. Cont. 
2.(i)WTC: South Africa-Egypt
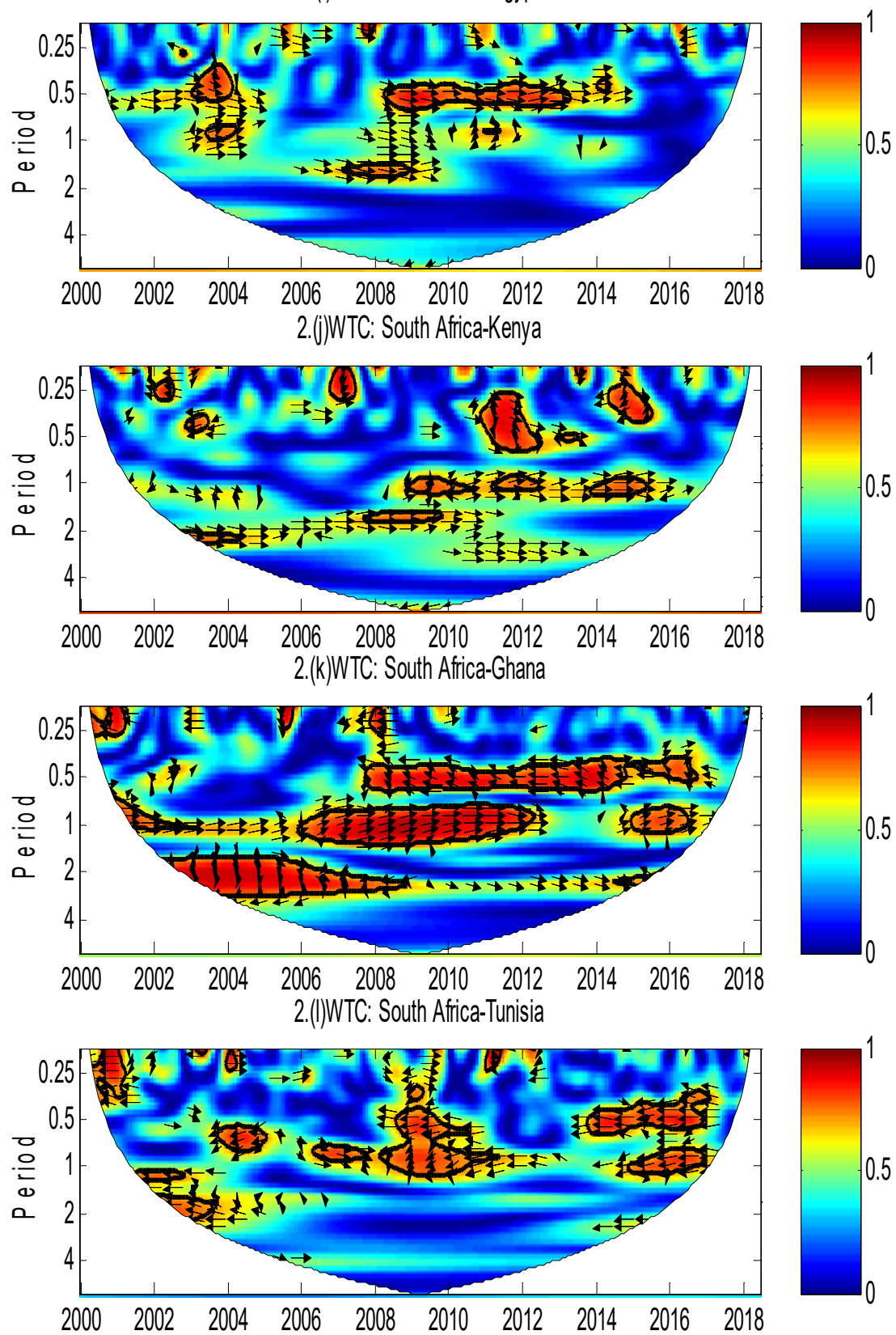

Figure 4. Cont. 
2.(m)WTC: South Africa-Botswana
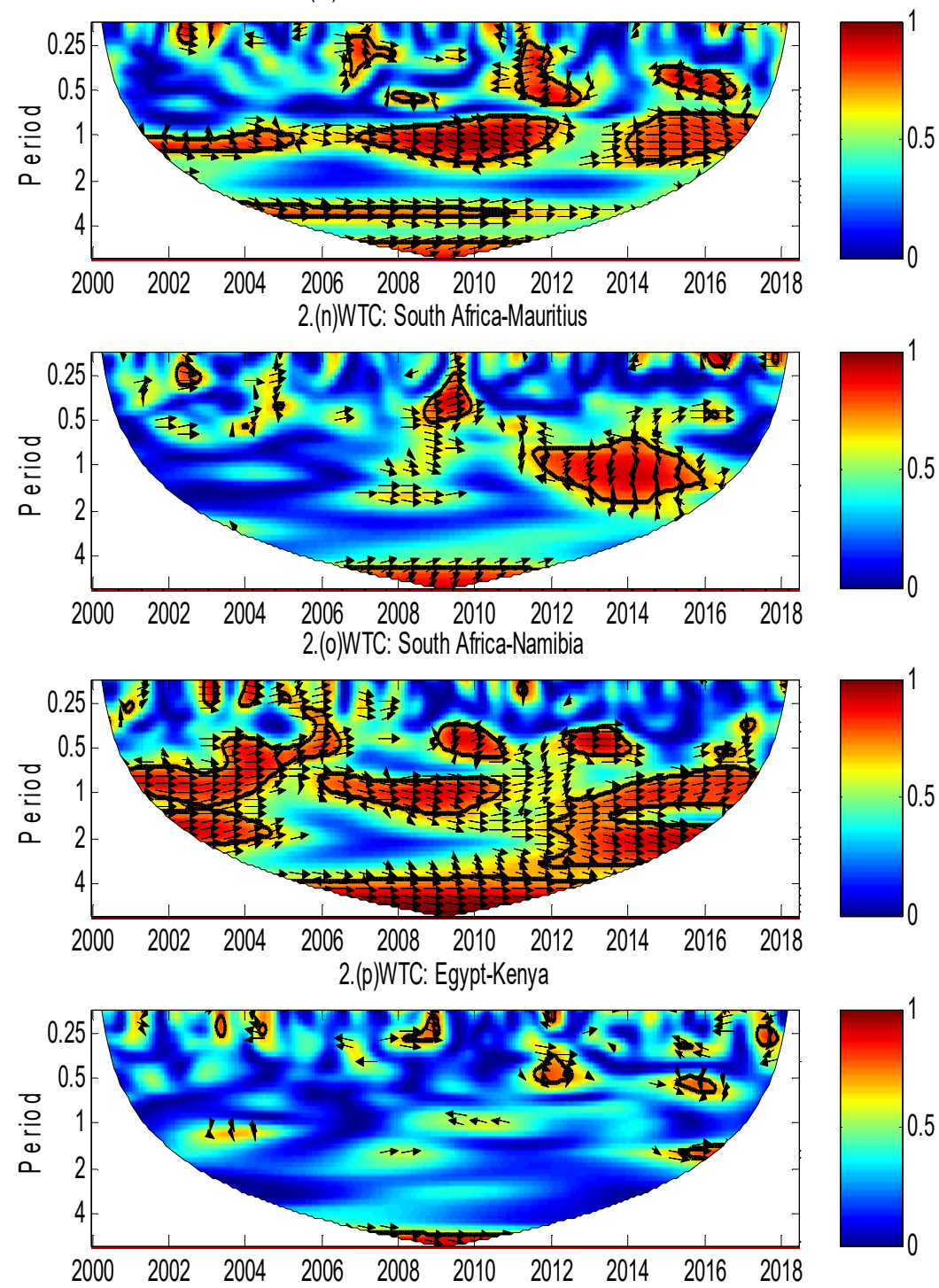

Figure 4. Cont. 
2.(q)WTC: Egypt-Ghana
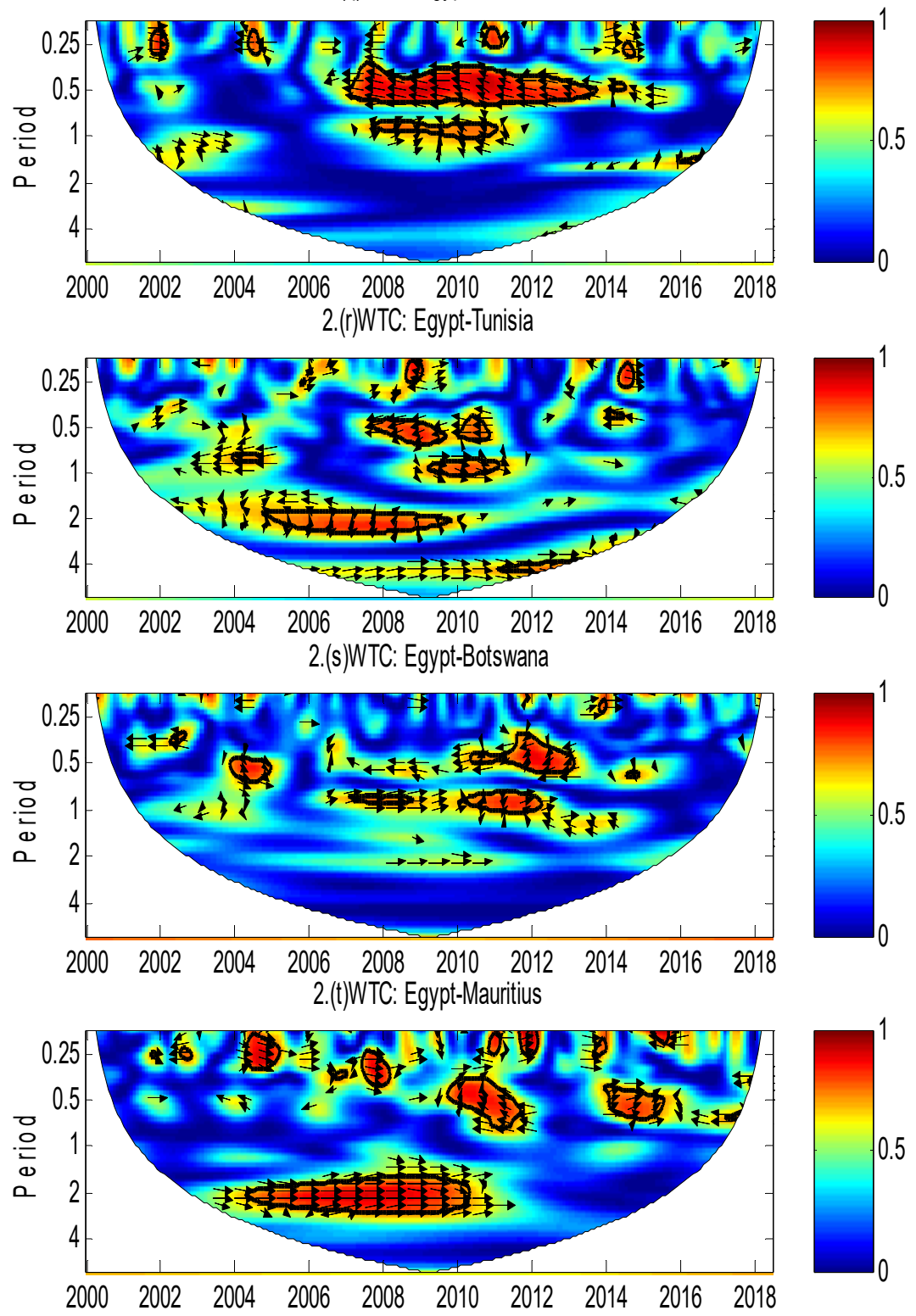

Figure 4. Cont. 

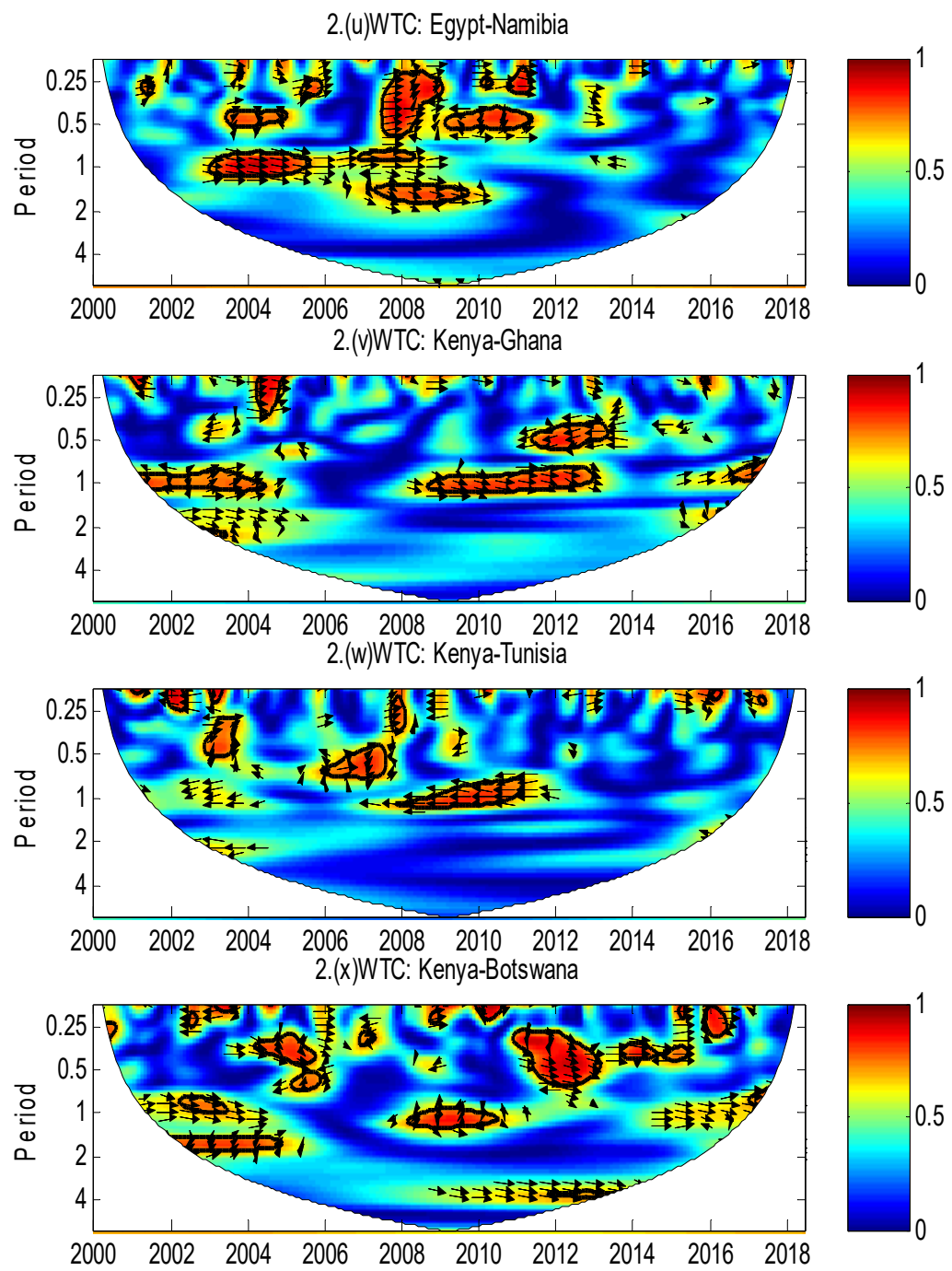

Figure 4. Cont. 
2.(y)WTC: Kenya-Mauritius
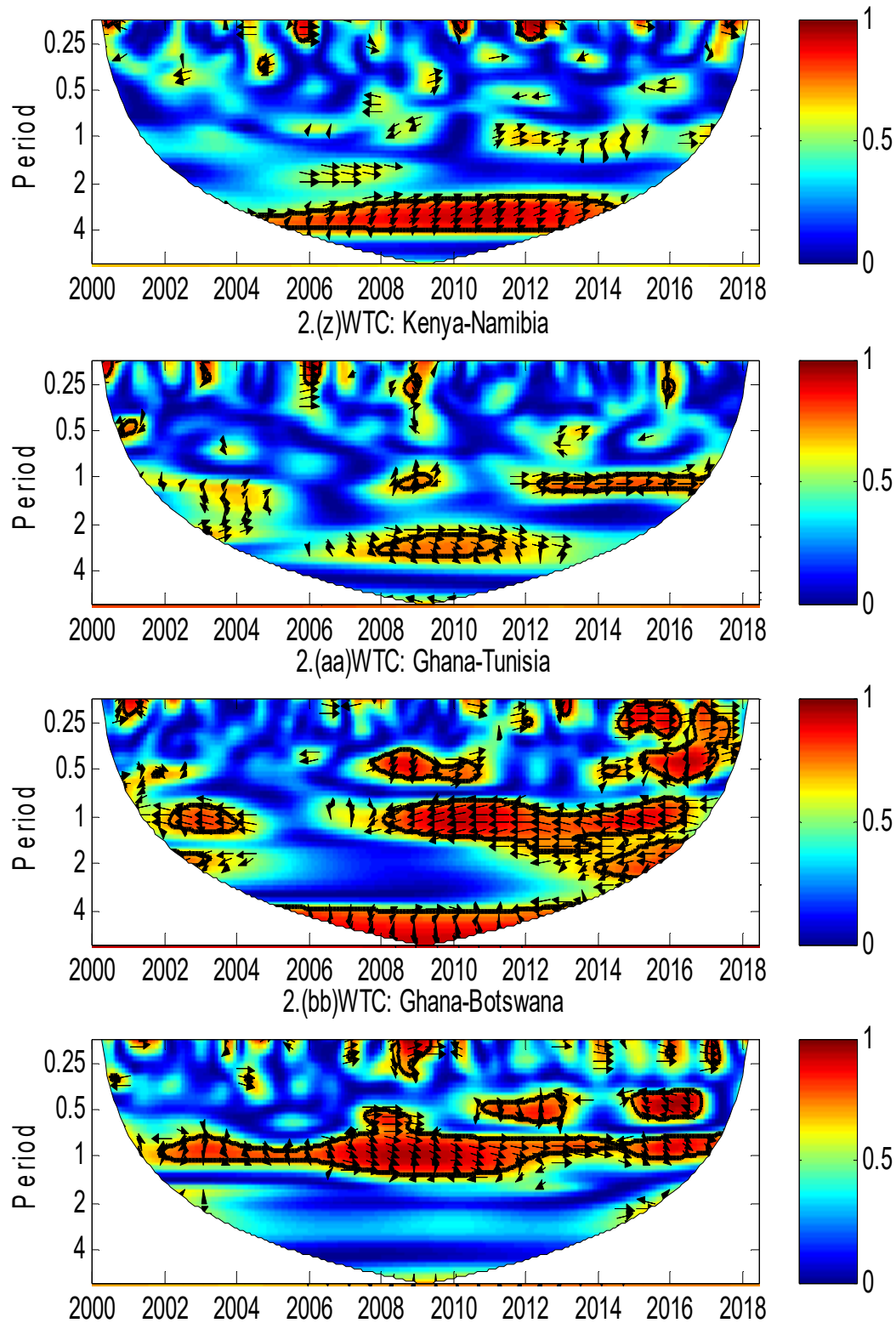

Figure 4. Cont. 

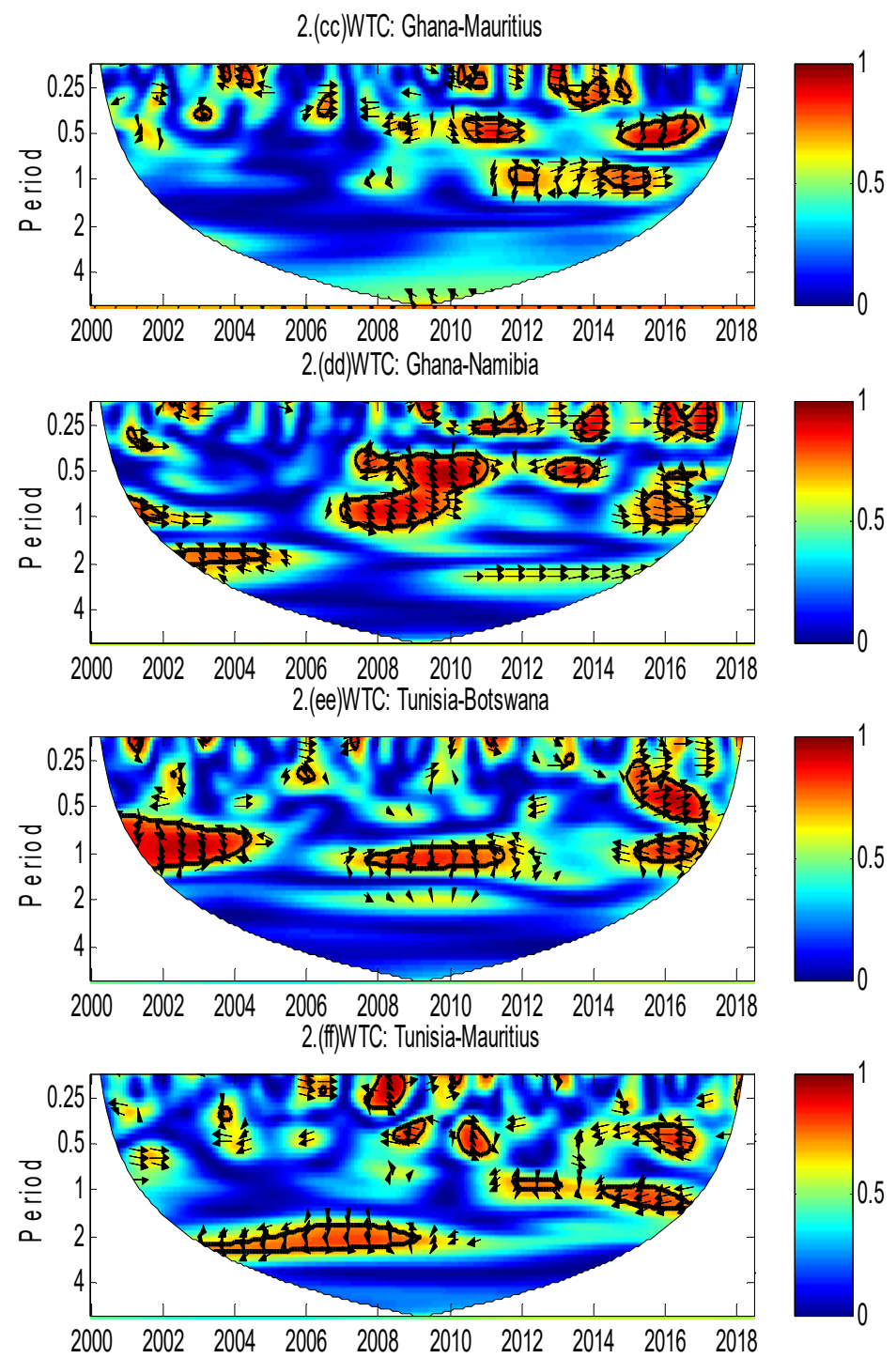

Figure 4. Cont. 

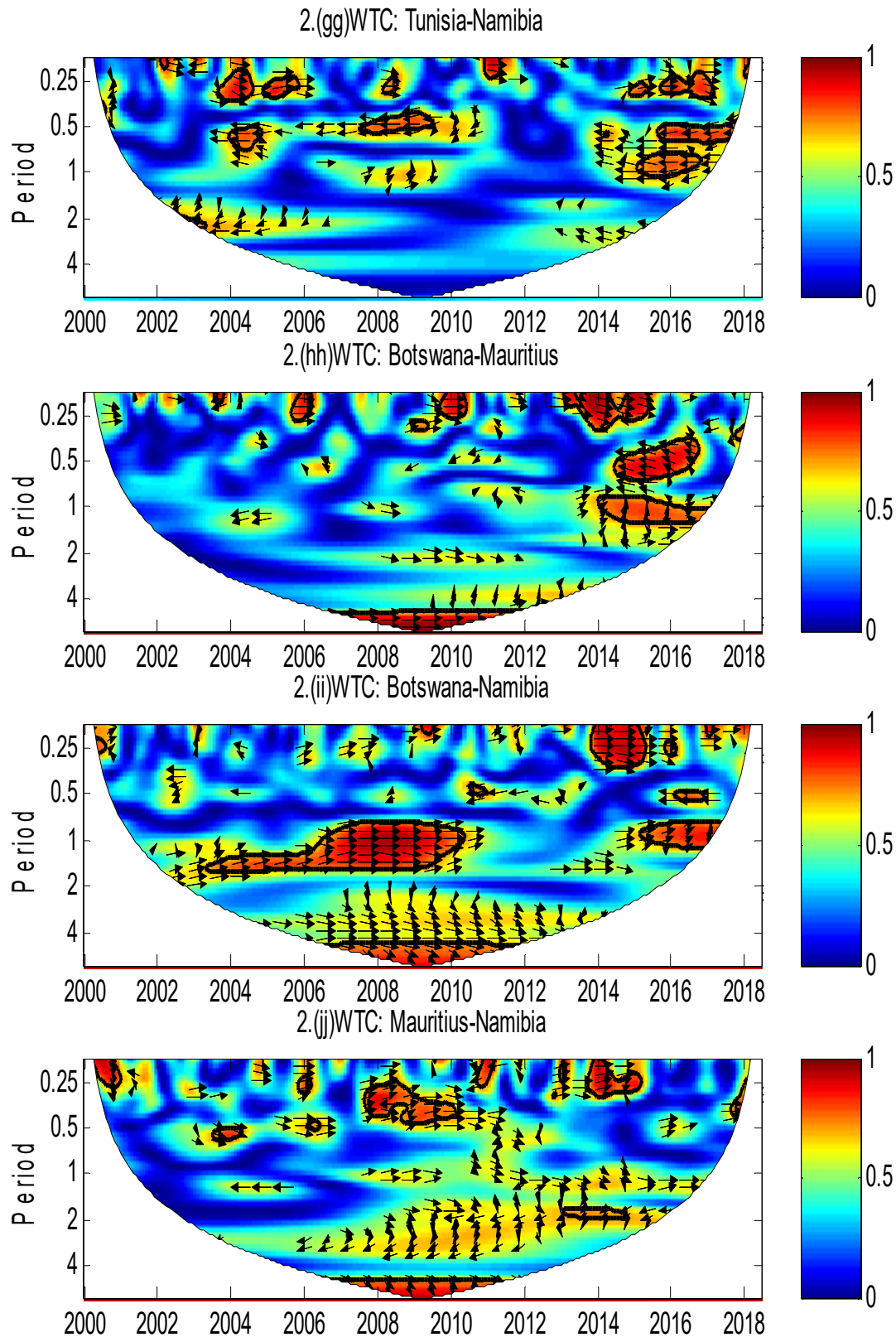

Figure 4. Pair wise wavelet coherency between selected nine African countries. 
WTC: Nigeria-USA
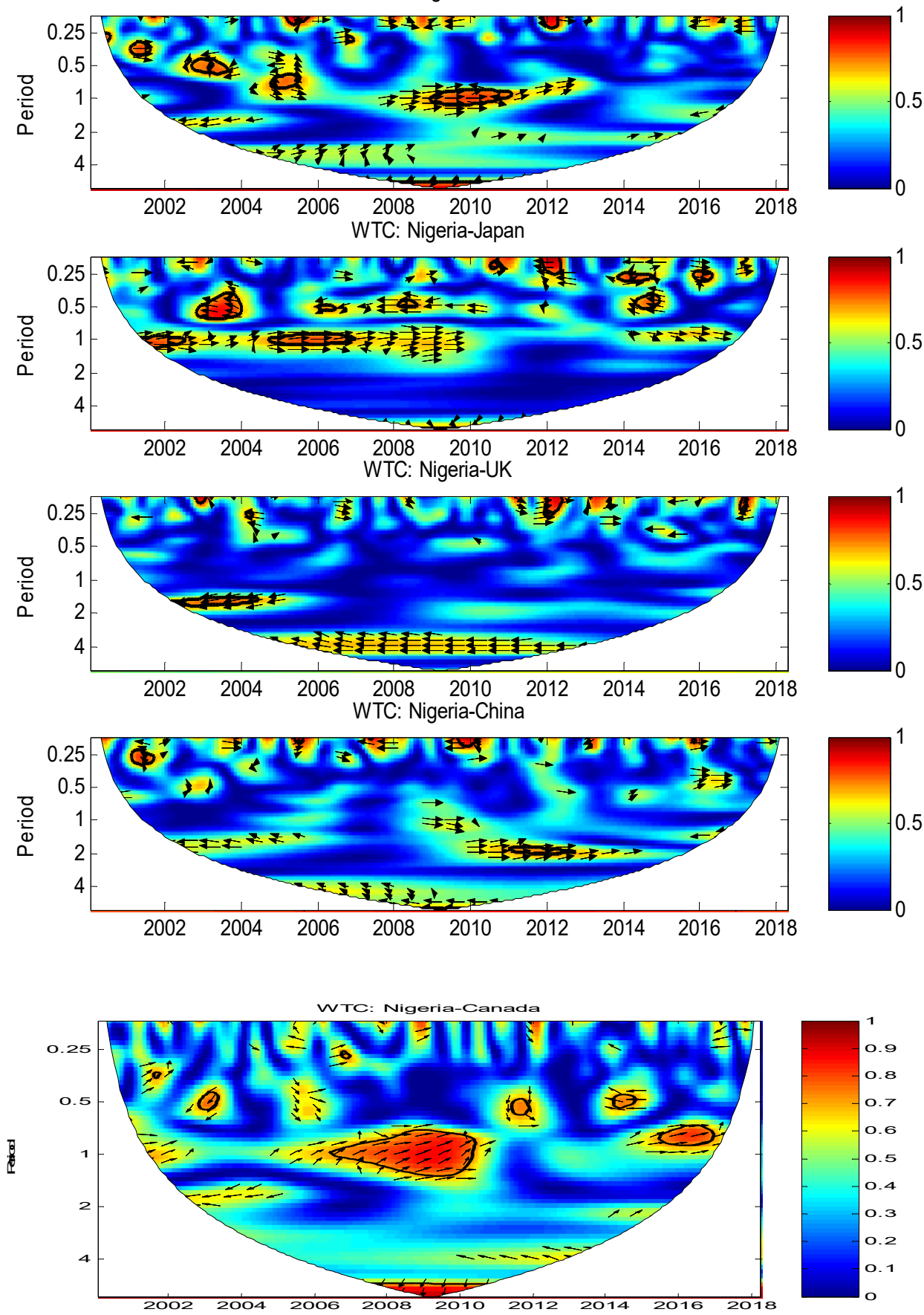

Figure 5. Cont. 
WTC: South Africa-USA
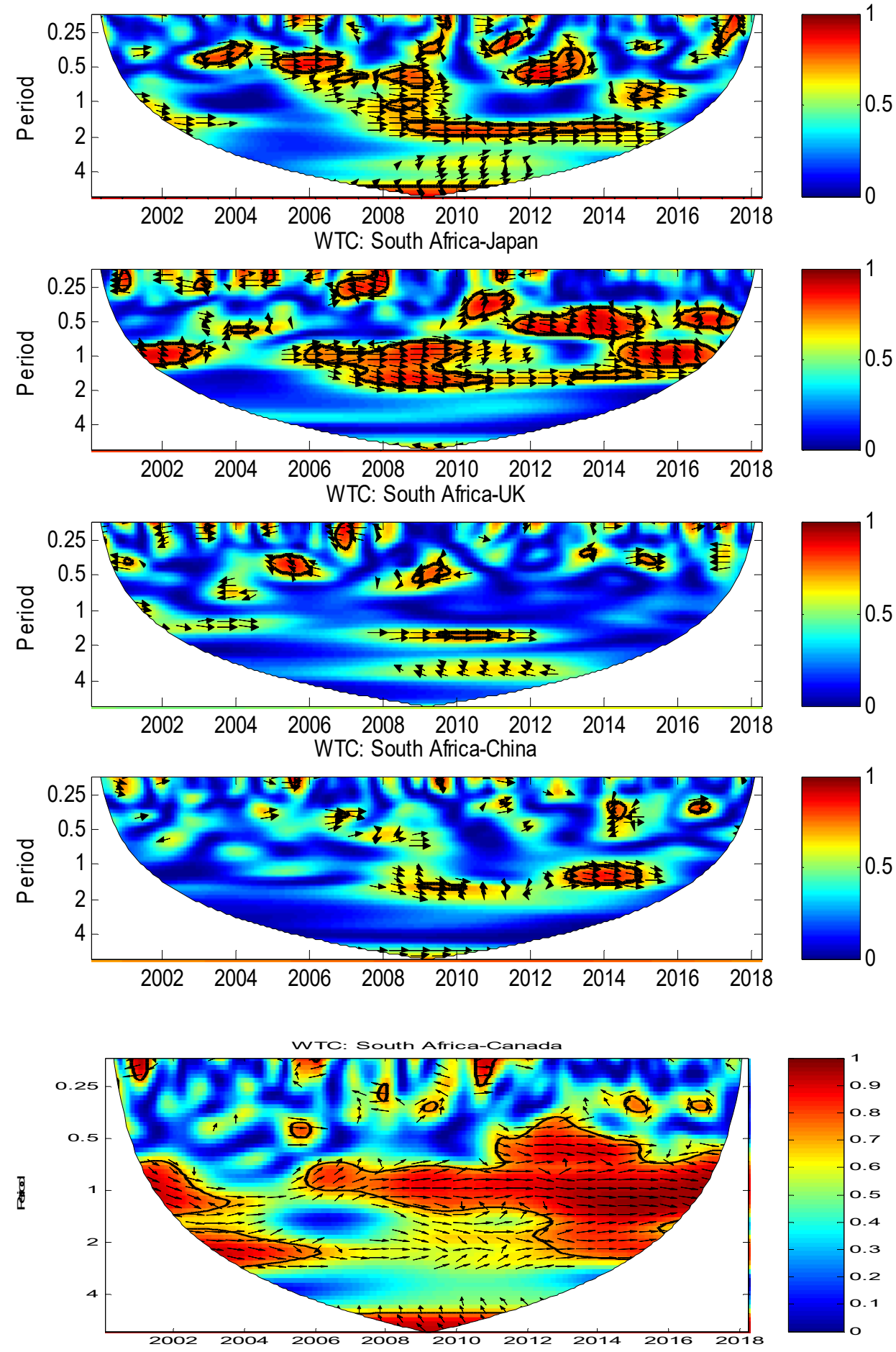

Figure 5. Cont. 

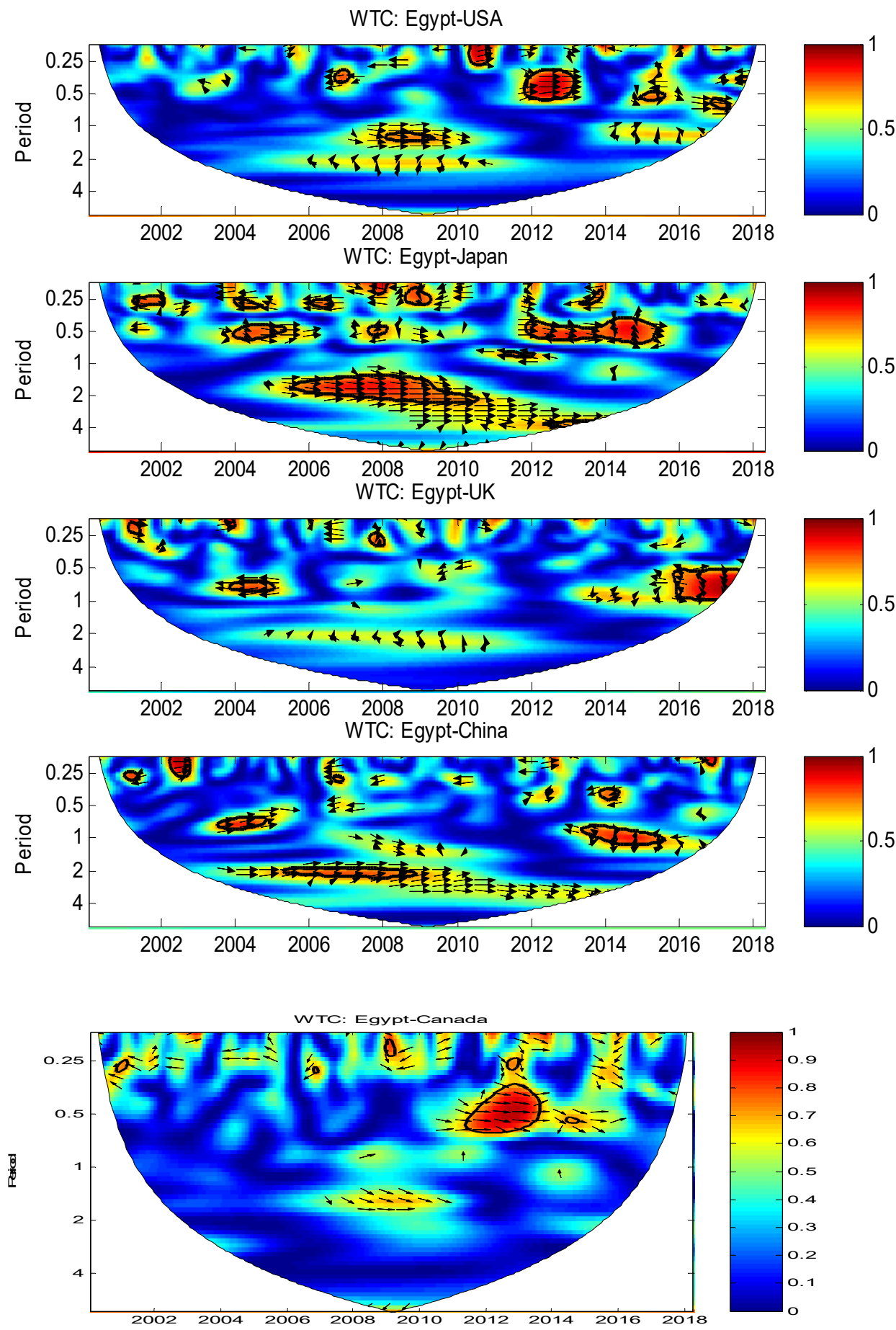

Figure 5. Cont. 
WTC: Kenya-USA
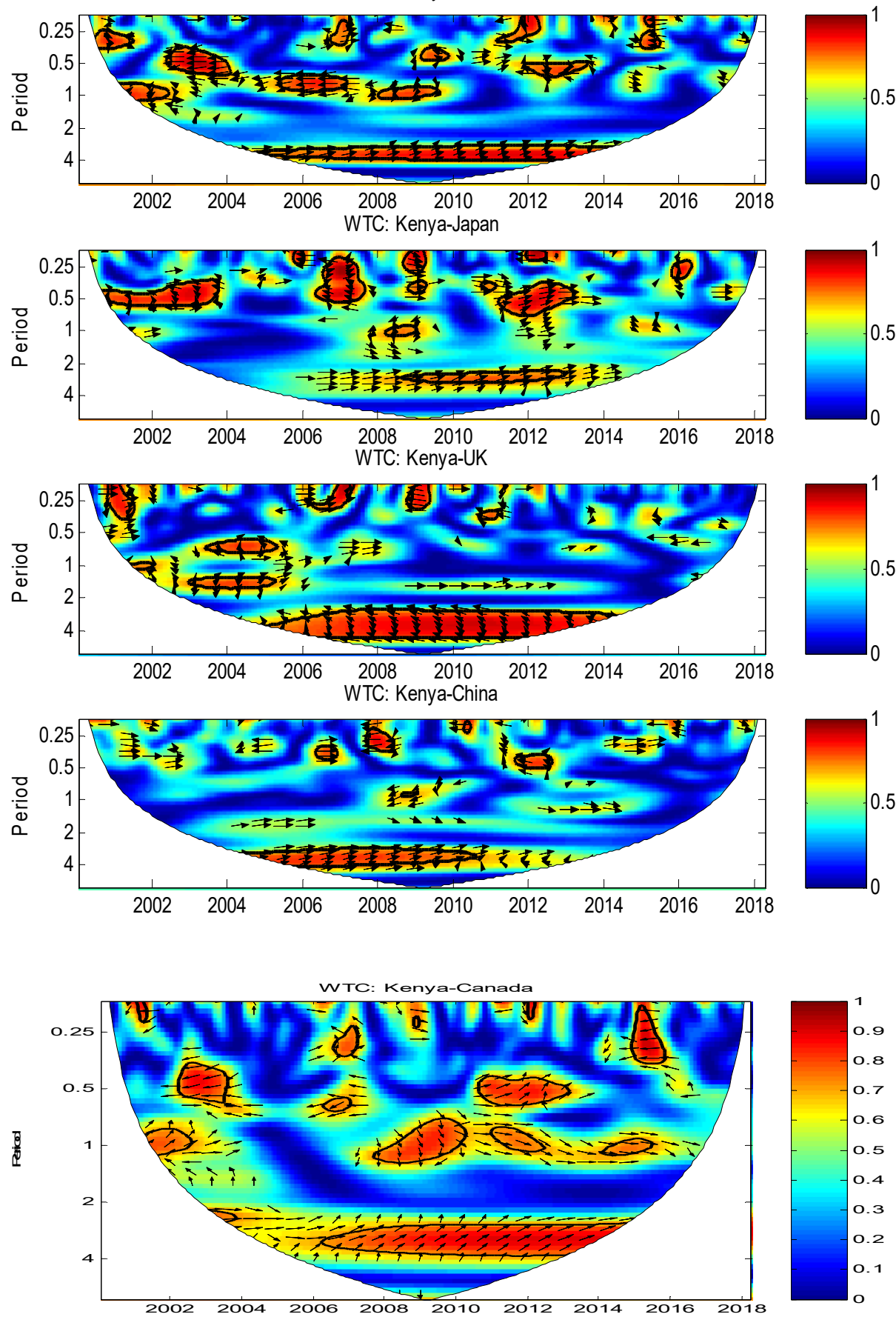

Figure 5. Cont. 

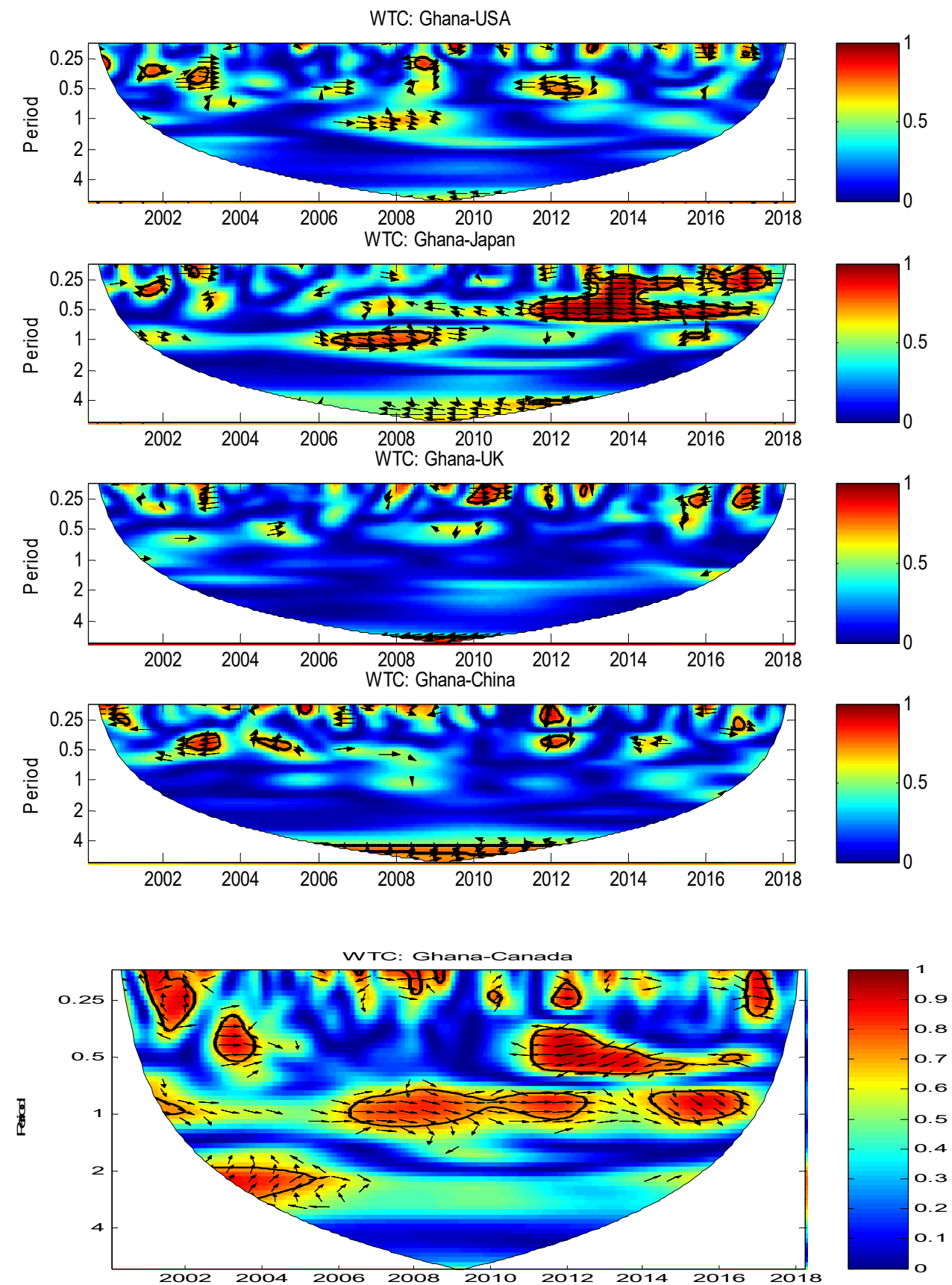

Figure 5. Cont. 
WTC: Tunisia-USA
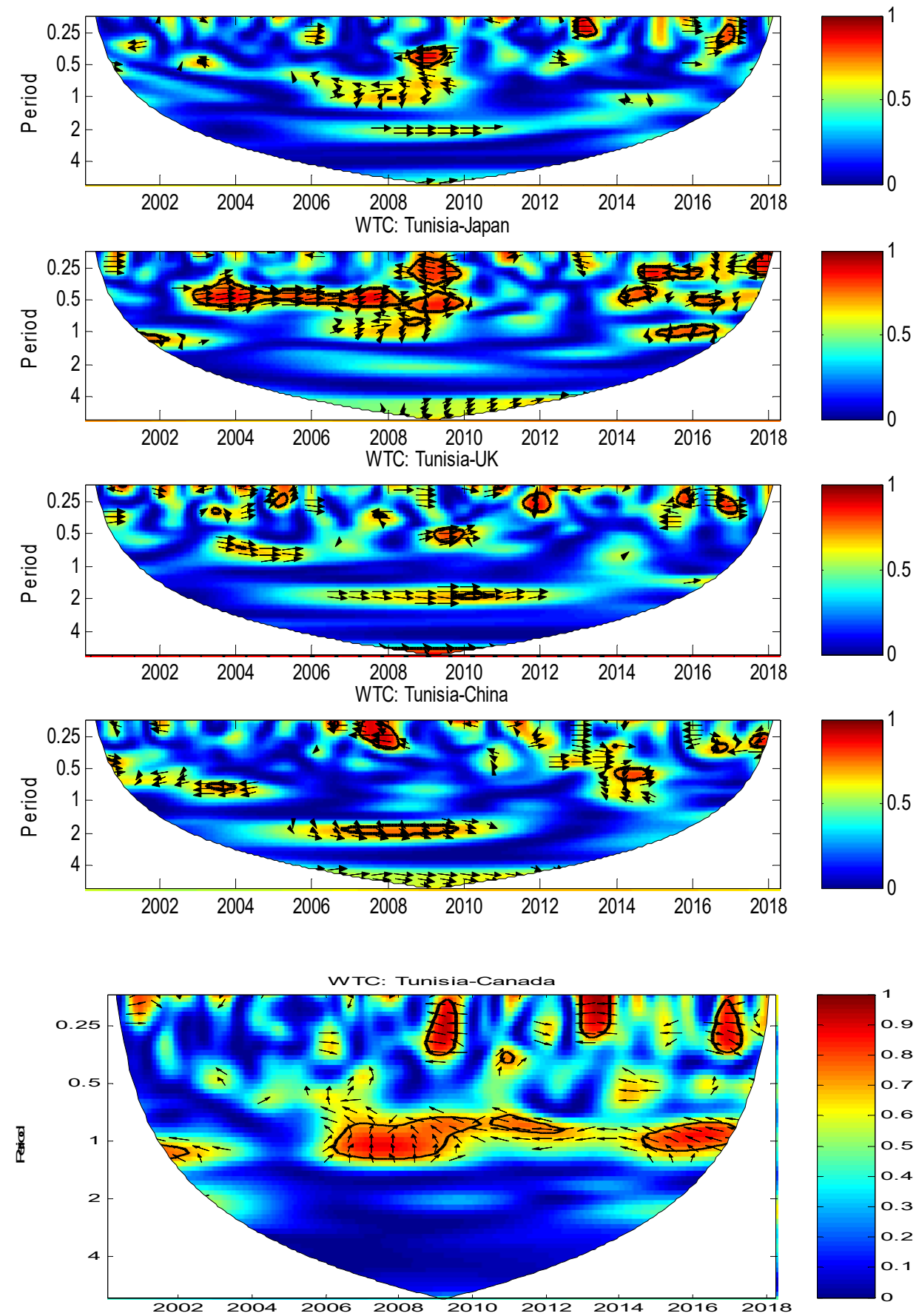

Figure 5. Cont. 
WTC: Botswana-USA
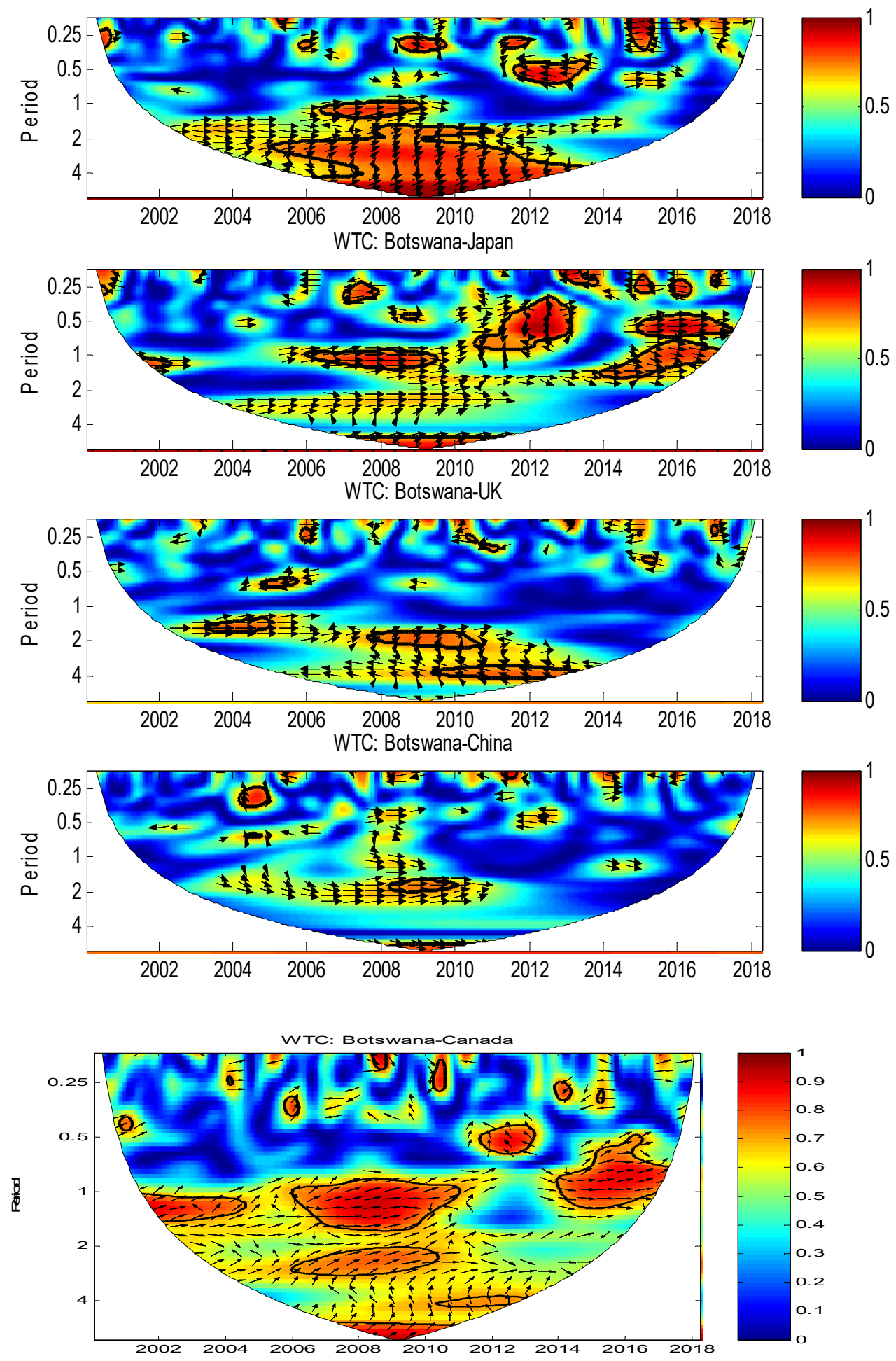

Figure 5. Cont. 
WTC: Mauritius-USA
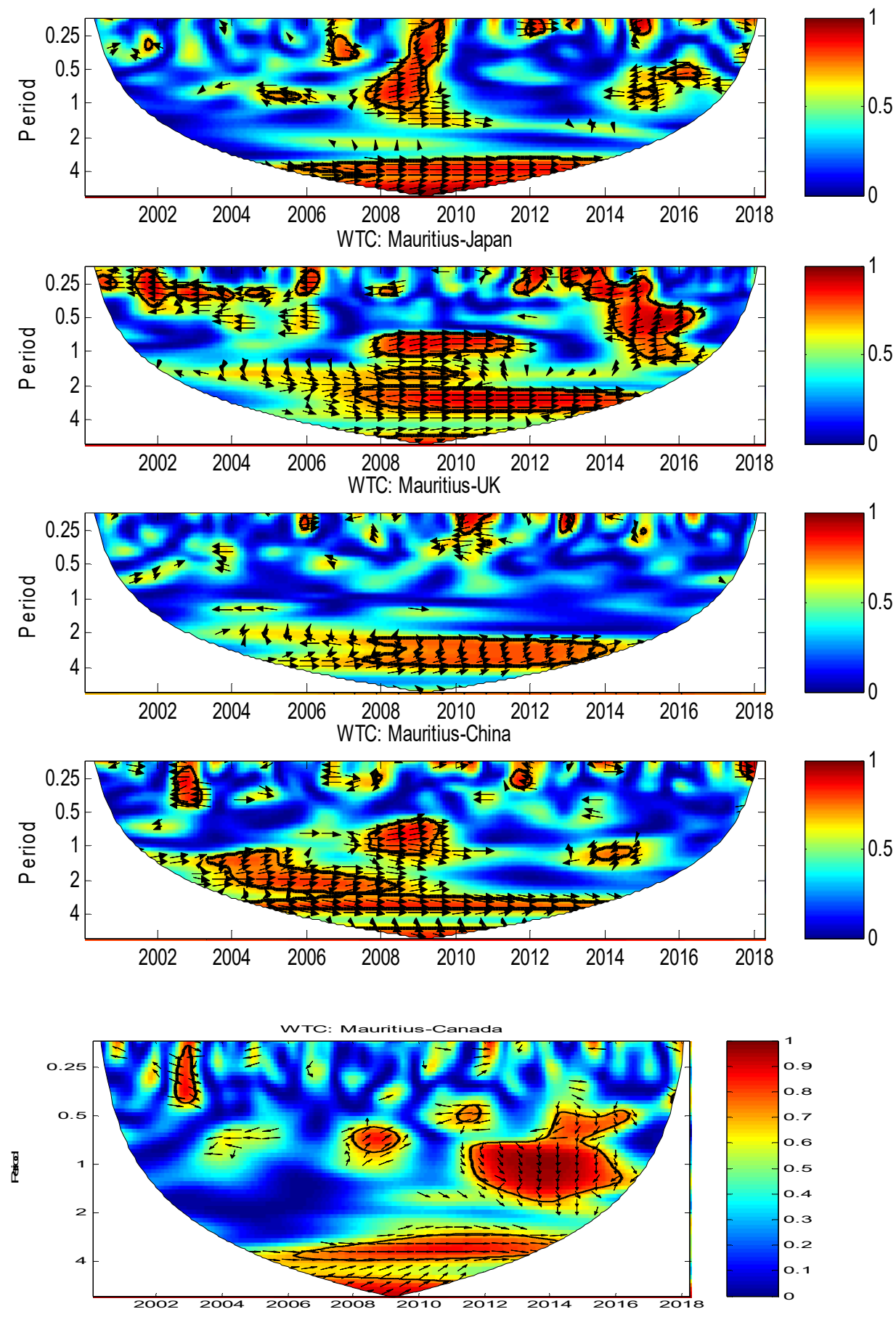

Figure 5. Cont. 
WTC: Namibia-USA
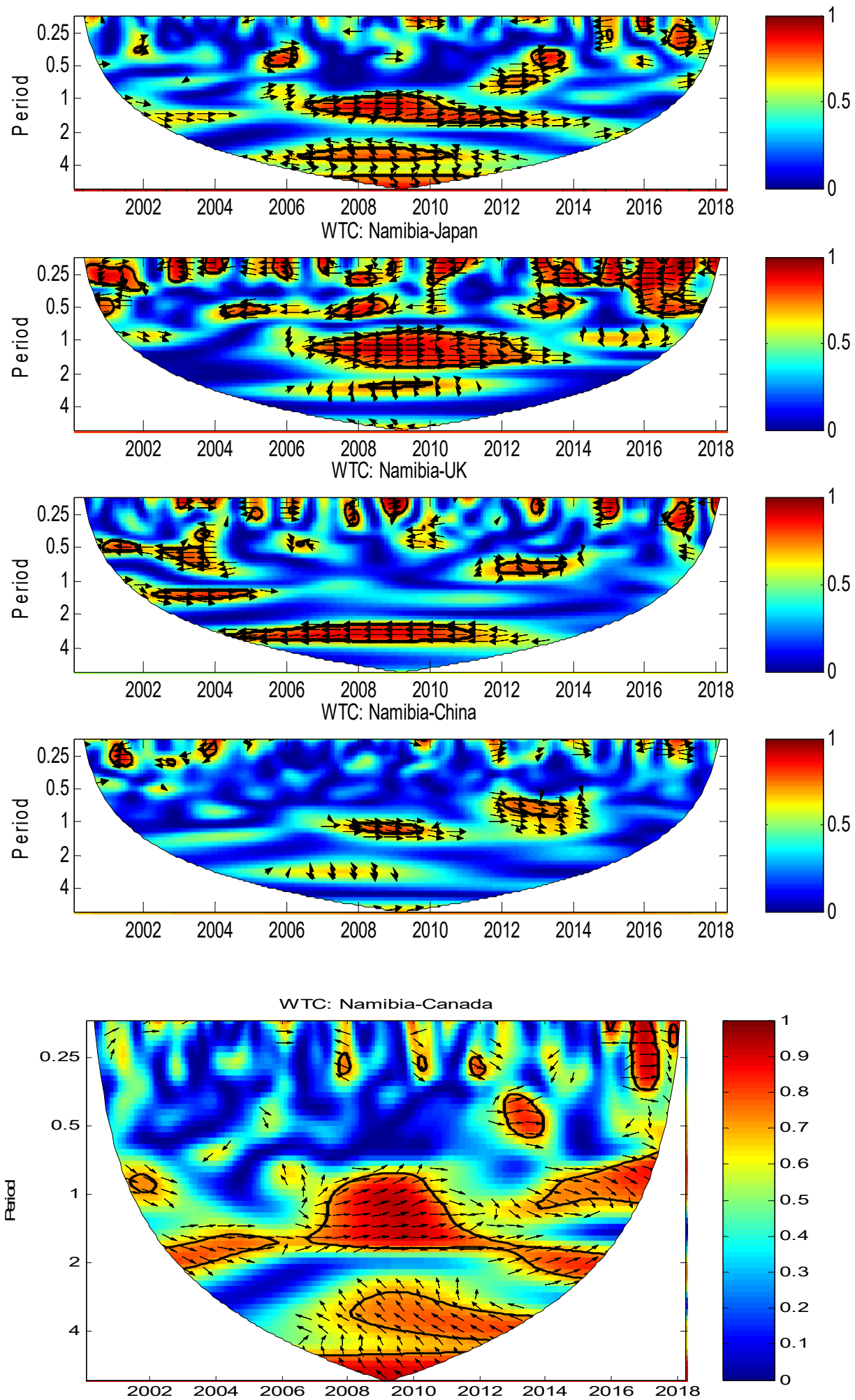

Figure 5. Pairwise wavelet coherency between selected nine African and five advanced countries.

From the graphs in Figures 4 and 5, it is clear that the co-movement of inflation rates is multi-scale for the pair of the countries under study. We find that at different time scales, there exists different magnitudes of inflation rate co-movements for the studied pair of countries, thus, inflation co-movement is seen to be time-varying. The evidence of inflation co-movement between African economies and the developed economies documented in 
this paper is not surprising. This is because, according to Ciccarelli and Mojon (2010), on average, up to $70 \%$ of the variation in a country's inflation rates can be explained by a common factor, and empirical evidence using different methodologies provides mixed evidence on the inflation co-movement in different countries. Similarly, Wang and Wen (2007), using calibrated New Keynesian two-country models, provide evidence that the co-movement in inflation rates is higher than the other economic variables. Thus, we find a common interpretational thread throughout the pairs of studied countries in Figures 4 and 5. For all studied country pairs, we see that inflation rates are correlated at medium to lower frequencies, which is in consonance with the findings of Tiwari et al. (2015), who examined inflation co-movement among G7 economies using time-frequency wavelets approaches. Also, it is evident that in both frequency and time domains, there are areas where we find no co-movements, or at least, insignificant co-movements. The novelty in our study rests on these findings, which could not have been obtained using conventional econometric techniques or wavelet techniques based on a discrete wavelet transform. That is, co-movements in inflation rates are not continuous, but rather discontinuous over time as well as over frequencies, in consonance with the findings of Tiwari et al. (2015). Using multiple correlations and multiple-cross-correlation-based wavelet analysis, Tiwari et al. (2015) investigated whether the inflation of four main European economies is synchronized. The results indicate that inflation correlations are stronger in the longterm. The authors conclude that similar monetary policies may be responsible for the high inflation correlation.

As we argued that inflation co-movement could be fueled by inflation spillover between countries in the sub-region, and, as a result, any two countries will exhibit inflation synchronization when inflation is high, we compare our earlier results obtained from the CWT synchronization measure of inflation co-movement with the Diebold and Yilmaz (2012) spillover index to measure inflation spillover between the selected nine African and five advanced economies. We thus compute a time-varying spillover index using a 90-month moving window. The results are presented in Figure 6, depicting the cumulative percentage of inflation spillover received by each of the 14 countries from the countries in our sample.

Results for Nigeria indicate that, on average, almost $85 \%$ of its inflation variance for the period under review is self-explained, followed by Canada, which accounts for about $10-15 \%$ of the total variation in Nigerian inflation. Surprisingly, results show total variation in Nigerian inflation is explained greatly by the developed economies. Canada, explaining 10-15\%, was followed by China, the UK, Japan, and the USA. For African countries, South Africa, a leading economy in Africa, explained about $5 \%$ of Nigerian inflation. The results for South Africa show that, on average, almost $90 \%$ of variation in South African inflation is explained by South Africa itself. This was followed by Canada, which accounted for almost $5-15 \%$ of South African inflation. Once again, a great percentage of variation in South African inflation was explained by the advanced economies of China, the UK, Japan, and the US, with Nigeria accounting for about $5 \%$ variance in South African inflation. The evidence that inflation across African economies can be explained by the advanced economies is in alignment with the conclusion of Neely and Rapach (2008), who documented that world and regional factors explain about $35 \%$ and $16 \%$, respectively, of inflation variability across the 64 countries. 

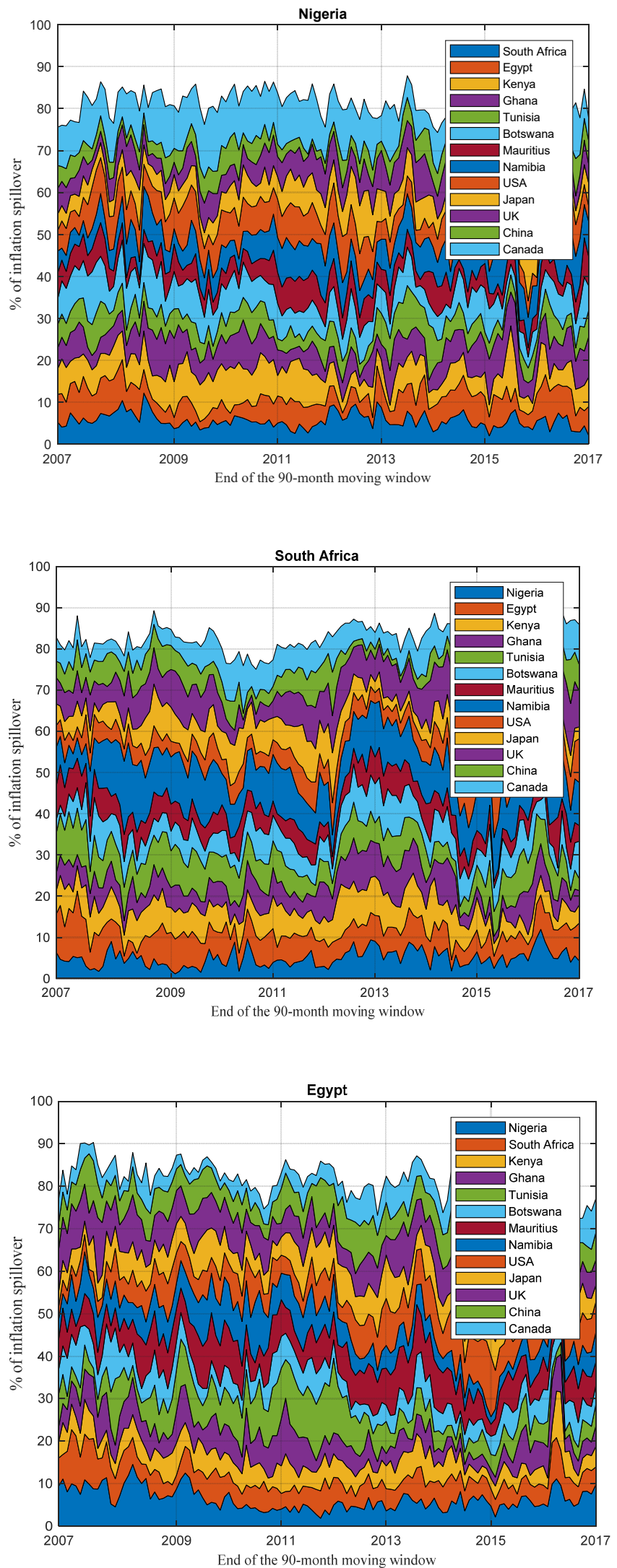

Figure 6. Cont. 

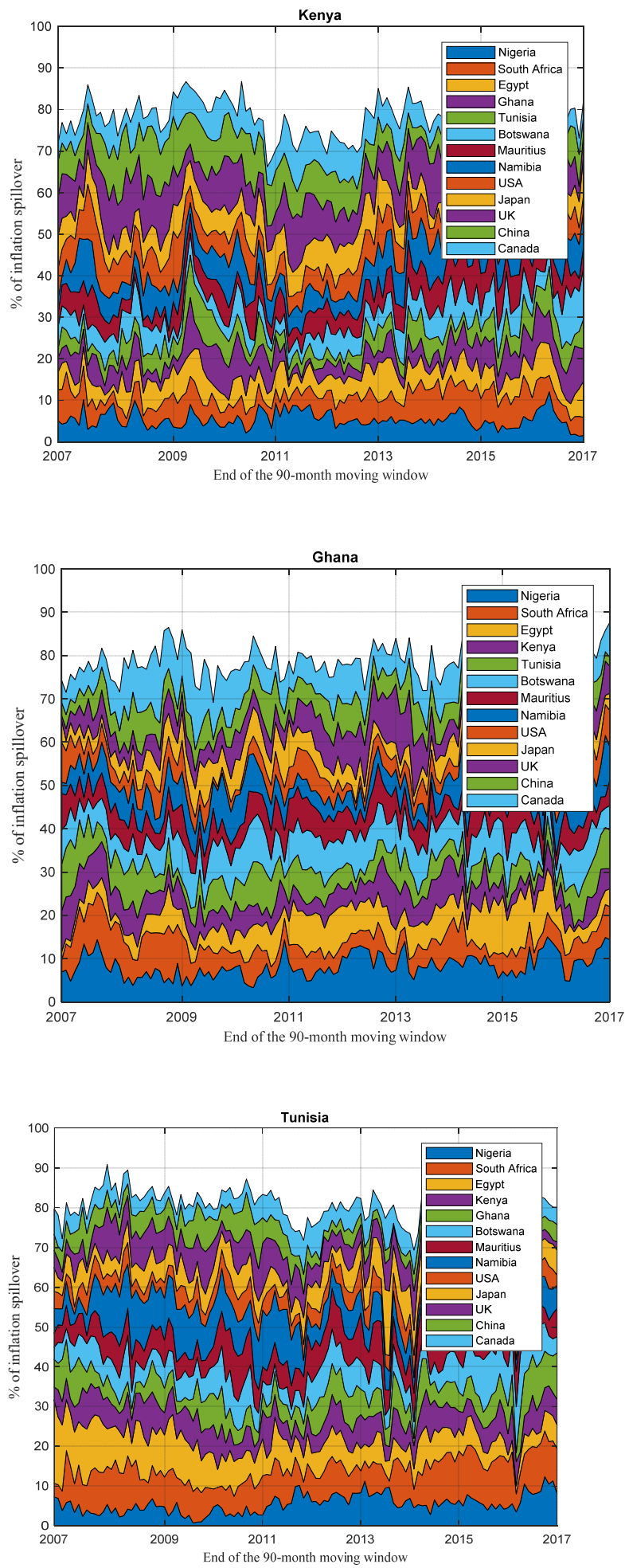

Figure 6. Cont. 

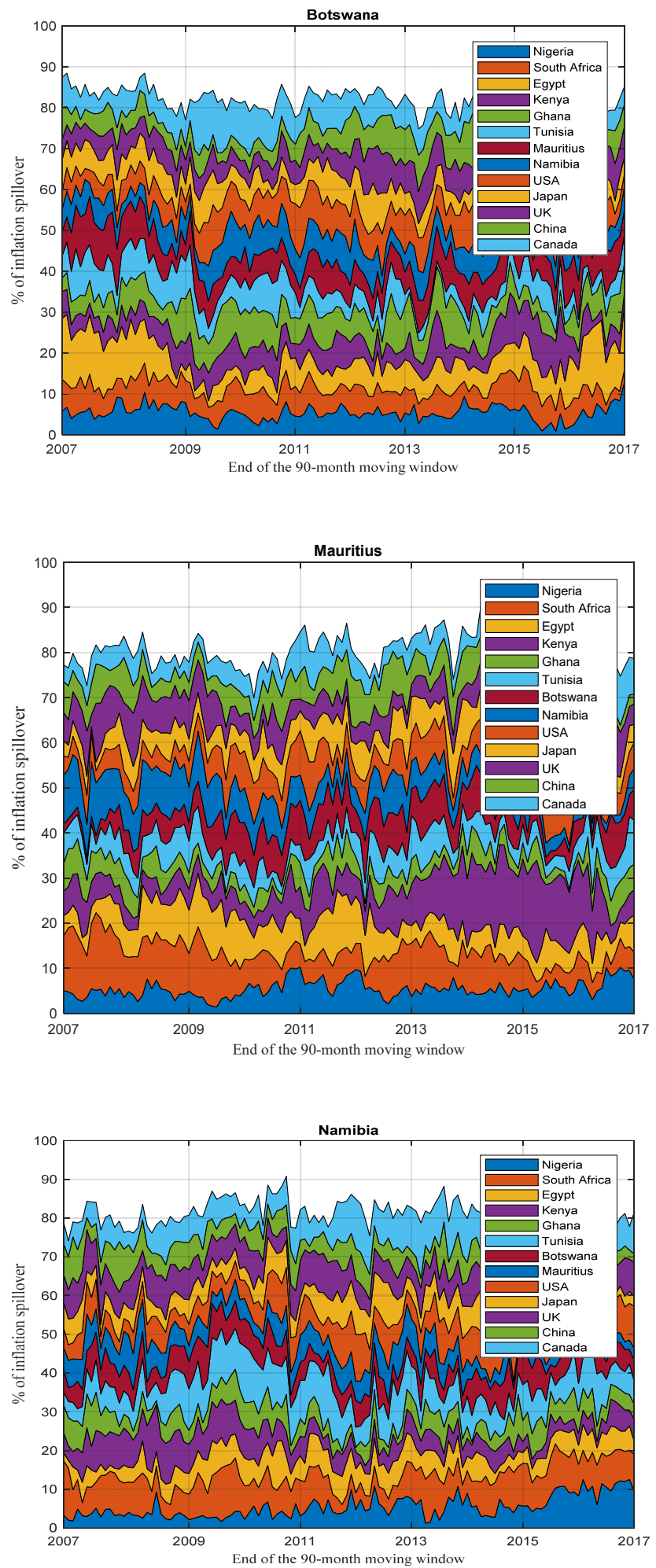

Figure 6. Cont. 

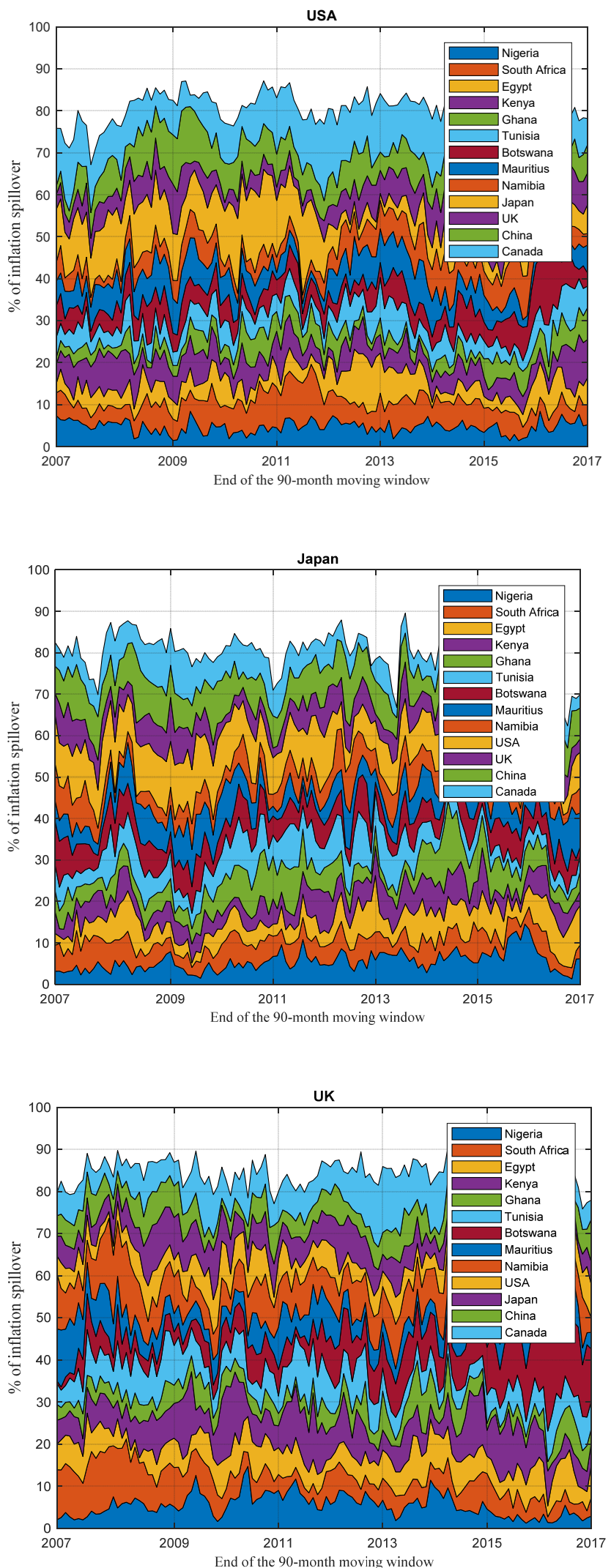

Figure 6. Cont. 

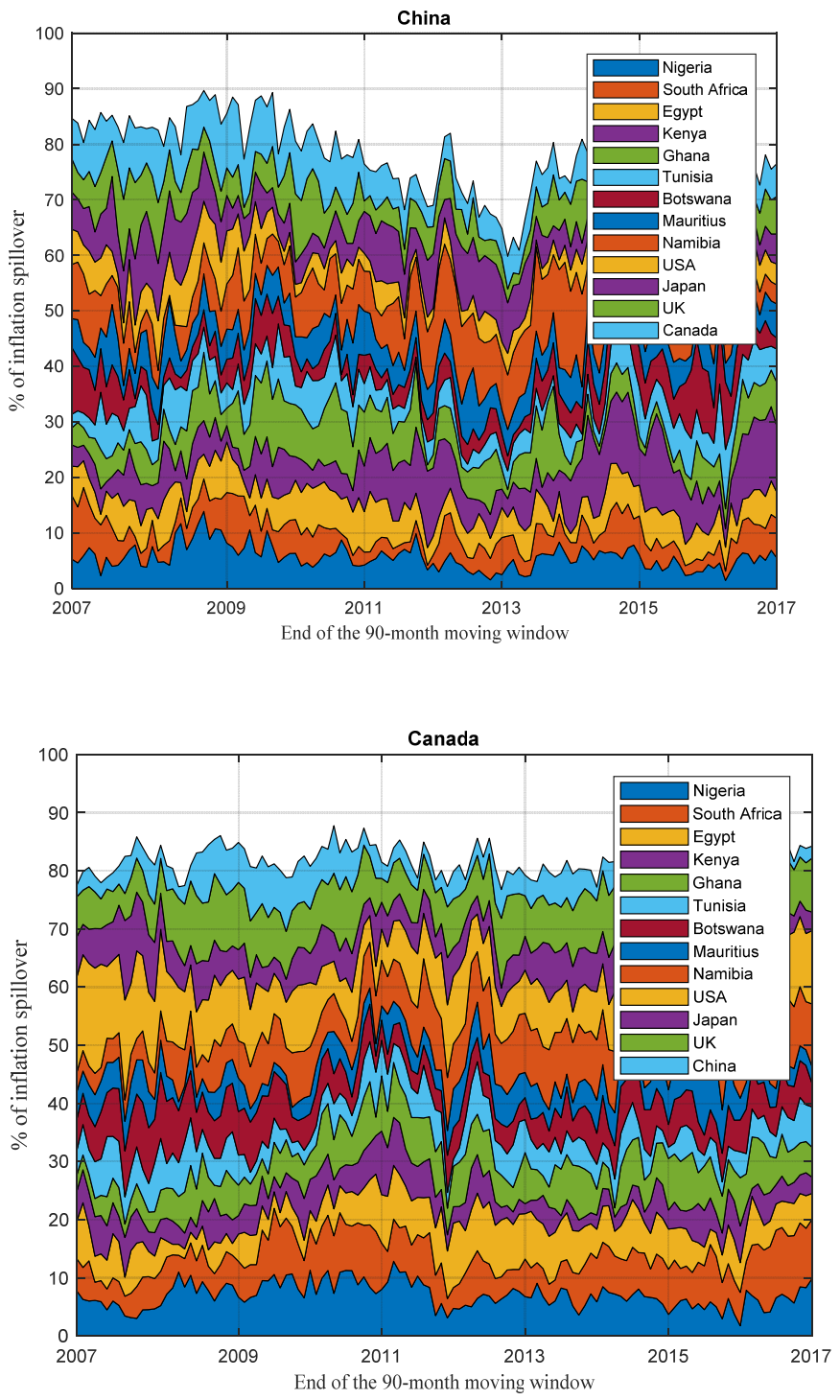

Figure 6. Inflation spill over across selected nine African and five advanced countries.

For the remaining African countries in our sample, these being Egypt, Kenya, Ghana, Tunisia, Botswana, Mauritius, and Namibia, we obtain similar findings to those obtained for South Africa and Nigeria. We find that, on average, almost $80 \%$ of inflation variation is accounted for by the individual countries. However, to our surprise, Canada emerged as the advanced country contributing most to the variation in Africa, followed by China. Thus, for African inflation, the variation is explained more by the advanced economies. This result could be explained by the historical liberal trade relations between African countries and the develop economies over several decades. With its massive capital investment and trade in Africa, China has influenced inflation variance greatly in Africa over the period under review. Quite interestingly, results show that Namibia contributes greatly to inflation variation in almost all the other African countries in our sample, with Nigeria accounting for the least variation of inflation in the African countries reported in our study. Results show Namibia's openness to trade and investment from global commerce. Moreover, we surmise that for Africa inflation, the percentage of variance explained by African countries is minimal, probably due to a lack of trade relations between African countries, thus, for each economy, the variance in inflation is explained by its own shocks. In fact, this could be the reason we find lower co-movement of inflation at most of the time scales across economies in the CWT diagrams. 
As anticipated, for the developed economies, we find that for US inflation, Canada explains almost $10-20 \%$ of total variation in US inflation. These findings are in consonance with the results reported by Tiwari et al. (2015), but differ from the findings of Yang and Guo (2006), who found that US inflation has a relatively larger influence on the inflation of Canada and the United Kingdom. As mentioned earlier, the impact of Canada inflation on US inflation is a similar finding to those documented by Tiwari et al. (2015). These results suggest that the strong trade relation between the US and Canada could be the driving force behind the strong inflation co-movement between these two countries. For the US, we see from the diagram that Nigeria and South Africa account for about $5-10 \%$ of variation in US inflation. For Canada, China, Japan, and the UK, we see that Nigeria, South Africa, and Egypt, on average, explain almost $5-20 \%$ of inflation variation in those countries. This could be because the majority of these countries trade with Africa for its natural resources, such as gold, oil, etc., thereby explaining the variation in inflation between these countries.

To further understand the co-movement in inflation for all country pairs, we compute the parameter estimates using the dynamic conditional correlation (DCC) model, with results reported in Table 3. The DCC plots are reported in Figure 7. We observe that in the mean equation, the coefficient estimated on the AR (1) term is insignificant and positive for Namibia, China, and the UK. For some countries, we find evidence of short-term persistence, since the estimated coefficient of the alpha1 term is significant for all countries except Kenya, Ghana, Tunisia, Botswana, Namibia, Canada, China, Japan, the UK, and the US. Additionally, we note that for countries where the estimate of the alpha1 term, signifying short-term persistence, is significant, we find the alpha1 is less compared to the estimate of beta1, which denotes long-term persistence. Clearly, we note the importance of longterm persistence across each series following the statistical significance of the estimated coefficient of beta1. Thus, volatility clustering is evident across the country's inflation, evidenced by the statistical significance of short-term persistence estimate, alpha1, and long term-persistence estimate, beta1. Next, we focus on the asymmetric term 'shape' estimated coefficient, with results showing that the asymmetric term is positive and insignificant for South Africa, Tunisia, Canada, and China. Thus, the inflation of these countries is increased by positive residuals. For the remaining countries, we find the asymmetric term to be positive and significant. This connotes that in the case of countries with a significant positive asymmetric term, negative residuals increase the conditional volatility compared to positive shock of the same magnitude. Leverage effects on different scale may be driven by diverse asymmetric information, heterogeneity, and arbitrage activities.

Table 3. Parameter estimates for the DCC model.

\begin{tabular}{ccccc}
\hline & Co-Efficient & Std. Error & t-Value & $\operatorname{Pr}(>|\mathbf{t}| \mathbf{~}$ \\
\hline Nigeria.mu & 0.768 & 0.045 & 17.012 & 0.000 \\
\hline Nigeria.ar1 & 0.348 & 0.087 & 4.009 & 0.000 \\
\hline Nigeria.omega & 0.005 & 0.004 & 1.165 & 0.244 \\
\hline Nigeria.alpha1 & 0.192 & 0.055 & 3.467 & 0.001 \\
\hline Nigeria.beta1 & 0.807 & 0.054 & 14.845 & 0.000 \\
\hline Nigeria.shape & 3.464 & 0.482 & 7.188 & 0.000 \\
\hline South.Africa.mu & 0.450 & 0.047 & 9.621 & 0.000 \\
\hline South.Africa.ar1 & 0.291 & 0.064 & 4.552 & 0.000 \\
\hline South.Africa.omega & 0.009 & 0.007 & 1.274 & 0.203 \\
\hline South.Africa.alpha & 0.047 & 0.024 & 1.945 & 0.052 \\
\hline South.Africa.beta1 & 0.900 & 0.050 & 18.110 & 0.000 \\
\hline South.Africa.shape & 15.345 & 13.563 & 1.131 & 0.258 \\
\hline Egypt.mu & 0.453 & 0.089 & 5.070 & 0.000 \\
\hline
\end{tabular}


Table 3. Cont.

\begin{tabular}{|c|c|c|c|c|}
\hline & Co-Efficient & Std. Error & t-Value & $\operatorname{Pr}(>|t|)$ \\
\hline Egypt.ar1 & 0.473 & 0.073 & 6.521 & 0.000 \\
\hline Egypt.omega & 0.013 & 0.015 & 0.851 & 0.395 \\
\hline Egypt.alpha1 & 0.152 & 0.040 & 3.815 & 0.000 \\
\hline Egypt.beta1 & 0.847 & 0.064 & 13.282 & 0.000 \\
\hline Egypt.shape & 3.930 & 0.806 & 4.879 & 0.000 \\
\hline Kenya.mu & 0.585 & 0.087 & 6.692 & 0.000 \\
\hline Kenya.ar1 & 0.445 & 0.070 & 6.372 & 0.000 \\
\hline Kenya.omega & 0.010 & 0.013 & 0.764 & 0.445 \\
\hline Kenya.alpha1 & 0.056 & 0.048 & 1.171 & 0.242 \\
\hline Kenya.beta1 & 0.928 & 0.051 & 18.316 & 0.000 \\
\hline Kenya.shape & 4.414 & 1.323 & 3.336 & 0.001 \\
\hline Ghana.mu & 1.181 & 0.178 & 6.624 & 0.000 \\
\hline Ghana.ar1 & 0.516 & 0.083 & 6.205 & 0.000 \\
\hline Ghana.omega & 0.424 & 0.490 & 0.865 & 0.387 \\
\hline Ghana.alpha1 & 0.532 & 0.373 & 1.425 & 0.154 \\
\hline Ghana.beta1 & 0.367 & 0.425 & 0.862 & 0.389 \\
\hline Ghana.shape & 3.585 & 0.867 & 4.136 & 0.000 \\
\hline Tunisia.mu & 0.319 & 0.032 & 9.839 & 0.000 \\
\hline Tunisia.ar1 & 0.256 & 0.067 & 3.847 & 0.000 \\
\hline Tunisia.omega & 0.000 & 0.005 & 0.074 & 0.941 \\
\hline Tunisia.alpha1 & 0.019 & 0.015 & 1.325 & 0.185 \\
\hline Tunisia.beta1 & 0.980 & 0.056 & 17.468 & 0.000 \\
\hline Tunisia.shape & 40.921 & 112.480 & 0.364 & 0.716 \\
\hline Botswana.mu & 0.421 & 0.061 & 6.951 & 0.000 \\
\hline Botswana.ar1 & 0.327 & 0.068 & 4.800 & 0.000 \\
\hline Botswana.omega & 0.067 & 0.049 & 1.379 & 0.168 \\
\hline Botswana.alpha1 & 0.228 & 0.180 & 1.266 & 0.206 \\
\hline Botswana.beta1 & 0.586 & 0.192 & 3.053 & 0.002 \\
\hline Botswana.shape & 3.224 & 0.812 & 3.968 & 0.000 \\
\hline Mauritius.mu & 0.329 & 0.038 & 8.621 & 0.000 \\
\hline Mauritius.ar1 & 0.225 & 0.074 & 3.029 & 0.002 \\
\hline Mauritius.omega & 0.009 & 0.049 & 0.186 & 0.852 \\
\hline Mauritius.alpha1 & 0.000 & 0.175 & 0.000 & 1.000 \\
\hline Mauritius.beta1 & 0.999 & 0.034 & 29.475 & 0.000 \\
\hline Mauritius.shape & 2.238 & 0.472 & 4.743 & 0.000 \\
\hline Namibia.mu & 0.426 & 0.038 & 11.304 & 0.000 \\
\hline Namibia.ar1 & 0.081 & 0.065 & 1.247 & 0.212 \\
\hline Namibia.omega & 0.000 & 0.000 & 0.000 & 1.000 \\
\hline Namibia.alpha1 & 0.000 & 0.000 & 0.001 & 0.999 \\
\hline Namibia.beta1 & 0.998 & 0.000 & 4988.132 & 0.000 \\
\hline Namibia.shape & 4.261 & 0.796 & 5.355 & 0.000 \\
\hline
\end{tabular}


Table 3. Cont.

\begin{tabular}{|c|c|c|c|c|}
\hline & Co-Efficient & Std. Error & t-Value & $\operatorname{Pr}(>|t|)$ \\
\hline Canada.mu & 0.165 & 0.086 & 1.918 & 0.055 \\
\hline Canada.ar1 & 0.211 & 0.100 & 2.105 & 0.035 \\
\hline Canada.omega & 0.000 & 0.061 & 0.001 & 0.999 \\
\hline Canada.alpha1 & 0.000 & 0.464 & 0.000 & 1.000 \\
\hline Canada.beta1 & 0.999 & 0.028 & 35.203 & 0.000 \\
\hline Canada.shape & 12.691 & 145.846 & 0.087 & 0.931 \\
\hline China.mu & 0.036 & 0.288 & 0.125 & 0.901 \\
\hline China.ar1 & 0.025 & 1.480 & 0.017 & 0.987 \\
\hline China.omega & 0.252 & 2.517 & 0.100 & 0.920 \\
\hline China.alpha1 & 0.394 & 2.190 & 0.180 & 0.857 \\
\hline China.beta1 & 0.000 & 8.108 & 0.000 & 1.000 \\
\hline China.shape & 5.115 & 6.251 & 0.818 & 0.413 \\
\hline Japan.mu & -0.007 & 0.015 & -0.450 & 0.653 \\
\hline Japan.ar1 & 0.224 & 0.056 & 3.987 & 0.000 \\
\hline Japan.omega & 0.000 & 0.000 & 0.434 & 0.664 \\
\hline Japan.alpha1 & 0.000 & 0.002 & 0.000 & 1.000 \\
\hline Japan.beta1 & 0.999 & 0.000 & 4542.099 & 0.000 \\
\hline Japan.shape & 3.598 & 0.826 & 4.355 & 0.000 \\
\hline UK.mu & 0.216 & 0.023 & 9.499 & 0.000 \\
\hline UK.ar1 & -0.076 & 0.049 & -1.568 & 0.117 \\
\hline UK.omega & 0.003 & 0.005 & 0.671 & 0.503 \\
\hline UK.alpha1 & 0.000 & 0.022 & 0.000 & 1.000 \\
\hline UK.beta1 & 0.976 & 0.019 & 52.087 & 0.000 \\
\hline UK.shape & 3.730 & 1.336 & 2.792 & 0.005 \\
\hline USA.mu & 0.193 & 0.021 & 9.046 & 0.000 \\
\hline USA.ar1 & 0.320 & 0.064 & 5.000 & 0.000 \\
\hline USA.omega & 0.013 & 0.009 & 1.415 & 0.157 \\
\hline USA.alpha1 & 0.226 & 0.118 & 1.908 & 0.056 \\
\hline USA.beta1 & 0.599 & 0.165 & 3.636 & 0.000 \\
\hline USA.shape & 4.759 & 1.460 & 3.260 & 0.001 \\
\hline Jointdcca1 & 0.000 & 0.000 & 0.204 & 0.839 \\
\hline Jointdccb1 & 0.956 & 0.021 & 46.115 & 0.000 \\
\hline Jointmshape & 10.193 & 1.020 & 9.998 & 0.000 \\
\hline \multicolumn{5}{|l|}{$\begin{array}{l}\text { Information } \\
\text { Criteria }\end{array}$} \\
\hline Akaike & 20.606 & & & \\
\hline Bayes & 23.343 & & & \\
\hline Shibata & 19.954 & & & \\
\hline Hannan-Quinn & 21.711 & & & \\
\hline Log-Likelihood & -2099 & & & \\
\hline No. Obs. & 221 & & & \\
\hline
\end{tabular}



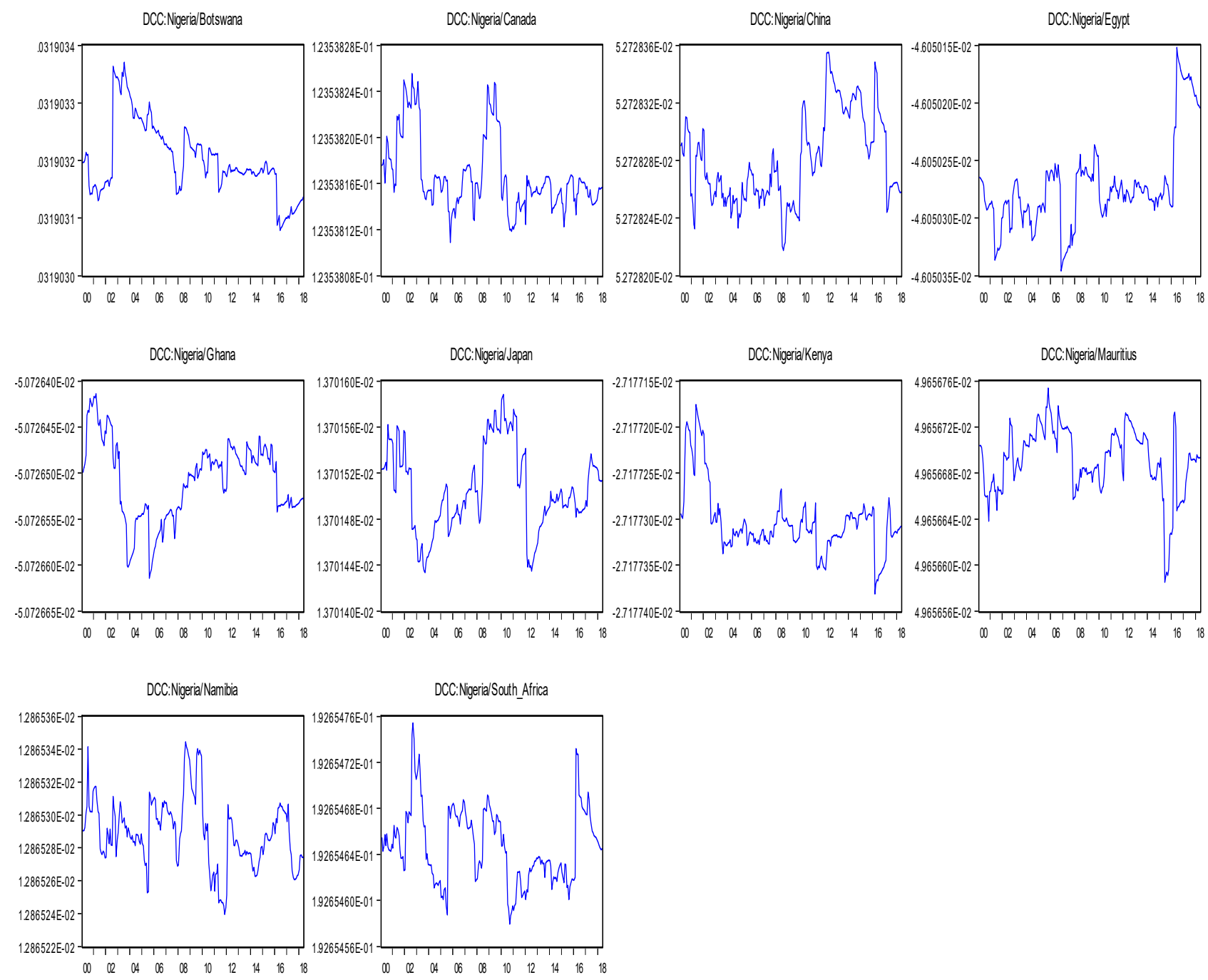

Figure 7. Dynamic conditional correlations plots between Nigeria and other countries. ${ }^{5}$

Using techniques based on a rolling window approach, we construct a one-stepahead dynamic conditional correlation between all country pairs' inflation, but only report estimates for Nigeria and other countries in Figure 7. For every 20 observations, the GARCH estimation models are refit. From Figure 7, we observe several interesting results. First, we note that the dynamic conditional correlation for Nigeria and all other countries differ. We observe an increasing and decreasing trend in negative and positive regions for the entire period at different points in time. In summary, a key observation from Figure 7 is the evidence of continual fluctuation for the entire period. The dynamic conditional correlation between the CPI of Nigeria and other countries under examination is timevarying.

\section{Summary and Conclusions}

This paper investigates inflation co-movement within nine African countries and five advanced economies using a frequency based cross-country co-movement of inflation rates. To study the synchronization of inflation across the selected countries at different period components of the inflation time series, we employed wavelet coherency based on a continuous wavelet transform. Results from the wavelet coherency indicate that co-movements of inflation are multi-scale in nature. Specifically, analyses document that inflation rates co-move across frequencies, and co-vary strongly with each other at low frequencies. We also find that inflation rate co-movement increases with time scales. Analysis 
of the country pairs shows that, at different time scales, there exist different magnitudes of inflation rate co-movement for the studied pair of countries, thus, inflation co-movement is seen to be time-varying. In addition, we find supporting evidence of frequent breaks in inflation co-variation at different time scales, which we attribute to country-specific reasons. Following results from the spillover index, we conclude that inflation rates in Africa are largely explained by inflation from advanced economies, something which we attribute to the bilateral trade between African and advanced economies. It is worth mentioning that South Africa, Nigeria, and Egypt explain, to some extent, inflation rate variation in the advanced countries.

The paper contributes to the literature in two aspects. First, this study is the first to have examined inflation rate co-movement in Africa and developed economies. Secondly, the novelty of this paper rests on the application of a methodology that has never been used to study inflation co-movement in the African-sub region and developed economies. Clearly, our findings will be of interest to policy-makers in the sub-region. We conclude that central banks in Africa needs to consider international inflation rates, and analyze their implications for their domestic economy, especially in the cases of Canada and China from the international front, and Nigeria, South Africa, and Egypt from the African region. However, focus should not be centered on global-inflation-related policies, but should consider inflation co-variation at different time frequencies. Additionally, it is essential that central banks in Africa consider their inflation targeting schemes under different time scales, especially in the medium- to long-term. The evidence of inflation spillover from one country to another in Africa is likely to decrease bond prices and increase the long-term yield of other countries. Hence, central banks should focus on protecting bond investors by adopting prudent and appropriate monetary policy strategies.

For future research, we recommend further studies be carried out on inflation comovement in Africa using a factor model framework to investigate how some common features, such as developments in the Sub-Saharan African region, business regulations, changes in oil prices, monetary policies, and exchange rate movements, explain the variability in domestic inflation. Lastly, a possible extension of this study could be investigating inflation spillover using quantile spillover model (Jena et al. 2021) and time-frequency spillover approaches (Le et al. 2021), which move away from the standard mean-based Diebold and Yilmaz (2012) model used in this paper, as well as copulas (Abakah et al. 2021; Tiwari et al. 2021), fractional cointegration techniques (Gil-Alana et al. 2020a, 2020b, 2021), and nonlinear causality techniques (Shahbaz et al. 2021).

Author Contributions: Conceptualization, investigation and software, A.K.T.; Conceptualization, Software, validation, formal analysis, data curation, writing original draft-E.J.A.A.; methodologyM.K.A.; writing-review and editing, L.A.G.-A. All authors have read and agreed to the published version of the manuscript.

Funding: Luis A. Gil-Alana gratefully acknowledges financial support from the Grant PID2020113691RB-I00 funded by MCIN/AEI/ 10.13039/ 501100011033. An internal Project from the Universidad Francisco de Vitoria is also acknowledged.

Data Availability Statement: Data available on request due to restrictions eg privacy or ethical.

Conflicts of Interest: The authors declare no conflict of interest.

\section{Notes}

1 The wavelet power spectrum is computed by taking a discrete Fourier transform of the time series. Then, for each scale, the wavelet's frequency response is analytically computed, and it is multiplied by the data's transform in the frequency domain.

2 The thick black contour designates the 5\% significance level against red noise and the cone of influence (COI), where edge effects that might distort the picture are shown in a lighter shade. The color code for power ranges from blue (low power) to red.

3 These edge effects arise due to periodicity assumptions in data and the response function of the wavelet. The artificial increase in the length of the time series to the next-higher power of two, by adding zero-value samples creates artificial discontinuities at the border of the data. As the wavelet gets closer to the edge of the time series, the values of the wavelet transform are affected by the zeros introduced, which creates the edge effect. 
4 The thick black contour designates the $5 \%$ significance level against red noise which is estimated from Monte Carlo simulations using phase randomized surrogate series. The cone of influence, which indicates the region affected by edge effects, is shown with a lighter shade black line. The color code for power ranges from blue (low power) to red (high power). The phase difference between the two series is indicated by arrows. Arrows pointing to the right mean that the variables are in phase. To the right and up, that $y$ is leading. To the right and down, that $y$ is lagging. Arrows pointing to the left mean that the variables are out of phase. To the left and up, that $y$ is lagging. To the left and down, that $y$ is leading.

5 We estimated DCC plots for all other country pairs, but reported only that of Nigeria and other countries. Remaining plots are available upon request.

\section{References}

Abakah, Emmanuel Joel Aikins, Emmanuel Addo Jr, Luis A. Gil-Alana, and Aviral Kumar Tiwari. 2021. Re-examination of international bond market dependence: Evidence from a pair copula approach. International Review of Financial Analysis 74: 101678. [CrossRef]

Aguiar-Conraria, Luís, and Maria Joana Soares. 2011. Oil and the macroeconomy: Using wavelets to analyze old issues. Empirical Economics 40: 645-55. [CrossRef]

Beck, Günter W., Kirstin Hubrich, and Massimiliano Marcellino. 2009. Regional inflation dynamics within and across Euro area countries and a comparison with the United States. Economic Policy 24: 141-84. [CrossRef]

Bernanke, Ben S. 2007. Globalization and Monetary Policy. Speech at the Fourth Economic Summit. Stanford: Stanford Institute for Economic Policy Research.

Calvo, Guillermo A., and Carmen M. Reinhart. 2002. Fear of floating. The Quarterly Journal of Economics 117: 379-408. [CrossRef]

Canzoneri, Matthew B., and Jo Anna Gray. 1985. Monetary policy games and the consequences of non-cooperative behavior. International Economic Review, 547-64. [CrossRef]

Ciccarelli, Matteo, and Benoit Mojon. 2010. Global inflation. The Review of Economics and Statistics 92: 524-35. [CrossRef]

Crowley, Patrick M., and David G. Mayes. 2009. How fused is the euro area core? OECD Journal: Journal of Business Cycle Measurement and Analysis 2008: 63-95. [CrossRef]

Dar, Arif Billah, Amaresh Samantaraya, and Firdous Ahmad Shah. 2013. The predictive power of yield spread: Evidence fromwavelet analysis. Empirical Economics. [CrossRef]

Daubechies, Ingrid. 1992. Ten Lectures on Wavelets. Philadelphia: SIAM Monographs.

Diebold, Francis X., and Kamil Yilmaz. 2012. Better to give than to receive: Predictive directional measurement of volatility spillovers. International Journal of forecasting 28: 57-66.

Devereux, Michael B., and Charles Engel. 2007. Expenditure switching versus real exchange rate stabilization: Competing objectives for exchange rate policy. Journal of Monetary Economics 54: 2346-74. [CrossRef]

Eickmeier, Sandra, and Katharina Moll. 2009. The Global Dimension of Inflation: Evidence from Factor-Augmented Phillips Curves. European Central Bank Working Paper No. 1011. Frankfurt: Johann Wolfgang Goethe University.

Gabor, Dennis. 1946. Theory of communications. Journal Institute of Electrical Engineers 93: 429-457. [CrossRef]

Gil-Alana, Luis Alberiko, Emmanuel Joel Aikins Abakah, and María Fátima Romero Rojo. 2020a. Cryptocurrencies and stock market indices. Are they related? Research in International Business and Finance 51: 101063. [CrossRef]

Gil-Alana, Luis Alberiko, Robert Mudida, and Emmanuel Joel Aikins Abakah. 2020b. Are central bank policy rates in Africa cointegrated? Evidence from a fractional cointegration approach. Applied Economics 52: 6171-82. [CrossRef]

Gil-Alana, Luis A., Emmanuel Joel Aikins Abakah, and Moses Kenneth Abakah. 2021. Financial stress spillover across Asian Countries. Review of Financial Economics 39: 146-62. [CrossRef]

Henriksen, Espen, Finn E. Kydland, and Roman Šustek. 2013. Globally correlated nominal fluctuations. Journal of Monetary Economics 60: 613-31. [CrossRef]

Jena, Sangram Keshari, Aviral Kumar Tiwari, Emmanuel Joel Aikins Abakah, and Shawkat Hammoudeh. 2021. The connectedness in the world petroleum futures markets using a Quantile VAR approach. Journal of Commodity Markets, 100222. [CrossRef]

Kose, M. Ayhan, Christopher Otrok, and Charles H. Whiteman. 2003. International business cycles: World, region, and country-specific factors. American Economic Review 93: 1216-39. [CrossRef]

Kose, M. Ayhan, Christopher Otrok, and Charles H. Whiteman. 2008. Understanding the evolution of world business cycles. Journal of International Economics 75: 110-30. [CrossRef]

Le, TN-Lan, Emmanuel Joel Aikins Abakah, and Aviral Kumar Tiwari. 2021. Time and frequency domain connectedness and spill-over among fintech, green bonds and cryptocurrencies in the age of the fourth industrial revolution. Technological Forecasting and Social Change 162: 120382. [CrossRef]

Liu, Paul C. 1994. Wavelet spectrum analysis and ocean wind waves. In Wavelets in Geophysics. Edited by E. Foufoula-Georgiou and P. Kumar. New York: Academic Press, pp. 123-51.

Madaleno, Mara, and Carlos Pinho. 2012. International stock market indices comovements: A new look. International Journal of Finance E Economics 17: 89-102.

Mallat, Stéphane. 1998. A Wavelet Tour of Signal Processing. San Diego: Academic Press.

Monacelli, Tommaso, and Luca Sala. 2009. The international dimension of inflation: Evidence from disaggregated consumer price data. Journal of Money, Credit and Banking 41: 101-20. [CrossRef] 
Mumtaz, Haroon, Saverio Simonelli, and Paolo Surico. 2011. International comovements, business cycle and inflation: A historical perspective. Review of Economic Dynamics 14: 176-98. [CrossRef]

Neely, Christopher J., and David E. Rapach. 2008. Real interest rate persistence: Evidence and implications. Federal Reserve Bank of St. Louis Review 90: 609-41.

Raihan, Sharif Md, Yi Wen, and Bing Zeng. 2005. Wavelet: A New Tool for Business Cycle Analysis. Working Paper Series 2005-050. St. Louis: Federal Reserve Bank of St. Louis.

Rua, António, and Luís C. Nunes. 2009. International comovement of stock market returns: A wavelet analysis. Journal of Empirical Finance 16: 632-39. [CrossRef]

Shahbaz, Muhammad, Nader Trabelsi, Aviral Kumar Tiwari, Emmanuel Joel Aikins Abakah, and Zhilun Jiao. 2021. Relationship between green investments, energy markets, and stock markets in the aftermath of the global financial crisis. Energy Economics, 105655. [CrossRef]

Tiwari, Aviral Kumar. 2012. Decomposing Time-Frequency Relationship between Interest Rates and Share Prices in India through Wavelets. MPRA Paper 39693. Munich: University Library of Munich.

Tiwari, Aviral Kumar. 2013. Oil prices and the macroeconomy reconsideration for Germany: Using continuous wavelet. Economic Modelling 30: 636-42. [CrossRef]

Tiwari, Aviral Kumar, Arif Billah Dar, and Niyati Bhanja. 2013a. Oil price and exchange rates: A wavelet based analysis for India. Economic Modelling 31: 414-22. [CrossRef]

Tiwari, Aviral Kumar, Mihai Mutascu, and Alin Marius Andries. 2013b. Decomposing time-frequency relationship between producer price and consumer price indices in Romania through wavelet analysis. Economic Modelling 31: 151-59. [CrossRef]

Tiwari, Aviral Kumar, Arif Billah Dar, Niyati Bhanja, and Aasif Shah. 2013c. Stock market integration in Asian countries: Evidence from wavelet multiple correlations. Journal of Economic Integration 28: 441-56. [CrossRef]

Tiwari, Aviral Kumar, Niyati Bhanja, Arif Billah Dar, and Olaolu Richard Olayeni. 2015. Analyzing time-frequency based co-movement in inflation: evidence from G-7 countries. Computational Economics 45: 91-109. [CrossRef]

Tiwari, Aviral Kumar, Emmanuel Joel Aikins Abakah, TN-Lan Le, and Dante I. Leyva-de la Hiz. 2021. Markov-switching dependence between artificial intelligence and carbon price: The role of policy uncertainty in the era of the 4th industrial revolution and the effect of COVID-19 pandemic. Technological Forecasting and Social Change 163: 120434. [CrossRef]

Torrence, Christopher, and Gilbert P. Compo. 1998. A practical guide to wavelet analysis. Bulletin of the American Meteorological Society 79: 61-78. [CrossRef]

Wang, Pengfei, and Yi Wen. 2007. Inflation dynamics: A cross-country investigation. Journal of Monetary Economics 54: $2004-31$. [CrossRef]

Yang, Jian, and Hui Guo. 2006. International transmission of inflation among G-7 countries: A data-determined VAR analysis. Journal of Banking E Finance 30: 2681-700. 